\title{
THE CLASSIFICATION OF MOUNTAINOUS BUILDINGS
}

\author{
Ahmed A. Fikry ${ }^{1}$, Abbas M. El Zafarany² \& Hala A. Nabil ${ }^{\mathrm{c}^{*}}$ \\ ${ }^{1}$ Architecture, Architecture Department, Faculty of Engineering, Cairo University, Egypt. \\ ${ }^{2}$ Environmental Design, Urban Design Department, Faculty of Urban planning, Cairo \\ University, Egypt. \\ ${ }^{3}$,Architecture Department, Faculty of Engineering, Cairo University, Egypt.
}

\begin{abstract}
The urbanization of Egypt is concentrated around the flat agricultural lands of the Nile Valley, which represent about 4\% of Egypt's area, where the deserts represent the most of Egypt territory. Despite the richness of Egypt territory of high lands, like mountains, hills and plateaus, the contemporary Egyptian completed his preference for flat plains extended to the flat lands of the desert. The highlands and mountains provide great opportunities for construction and development in Egypt, especially for tourism sector. However, the scientific expertise is an important element to know how to build in mountainous areas, so the demand for the guidelines and the scientific foundations are substantial. The paper aims to classify the mountain buildings because the possibility of classifying will guide the designers to be able to construct in mountainous areas. The intersection between different types of Architectural classifications and definitions, and the merging of some mountain building classifications under other architectural classifications have led to the marginalization of the mountain Architecture. Therefore, these definitions will be clarified according to architects and experts studies. The buildings will be classified architecturally according to their relationship to the mountains. As the study on the architectural scale of the building, the classification will based upon the intersection with the mountain mass, which in circumstance is determined by many factors such as angle of inclination, rock nature, surrounding location, and building area. The research will highlight on how to deal with the mountainous areas as a place to settle and live with various limitations and conditions.
\end{abstract}

\section{Keywords: Architectural Classification; Architectural Definition; Highlands; Mountain Dwellings; Mountains}

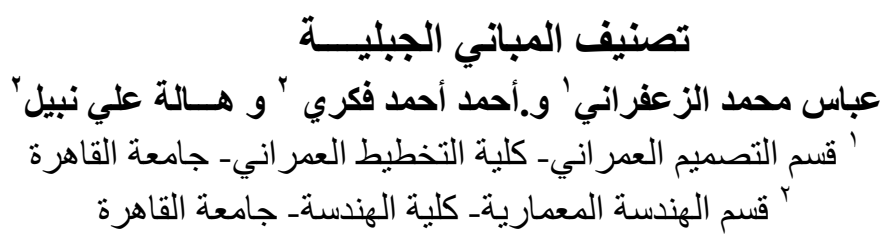

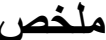

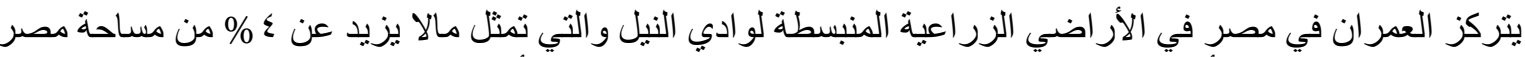

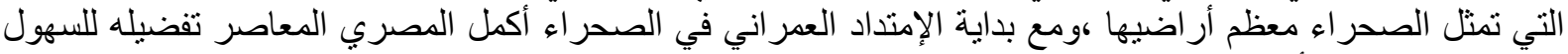

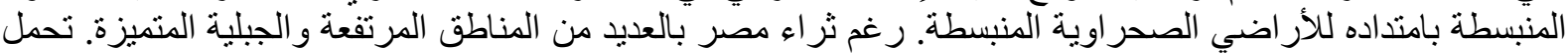

المرتفعات و الجبال فرصا كبيرة للتعمير والتنمية وخاصة المجاءل التبال السياحي، ولكن يتطلب الأمر الخبرة العلمية في كيفية

التعامل للبناء بالجبال في مصر، لذا تبدو الحاجة لوضع الخطوط العريضة و الأسس التي تتناول كيفية البناء بالمناطق فئة
}

* Corresponding Author: Tel.: +02 01227056563

E-mail address: halanabil_eng@yahoo.com. 
الجبلية. ولذلك فإن الهدف من الورقة البحثية هو كيفية تصنيف المباني الجبلية وبالتالي كيفية التصميح و البناء بتلك المناطق

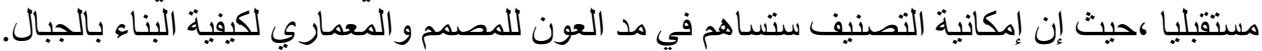

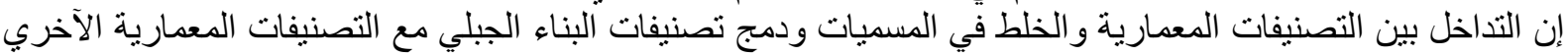

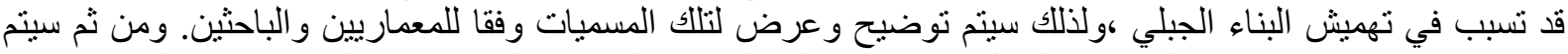

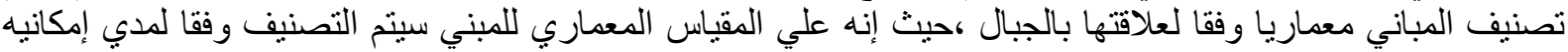

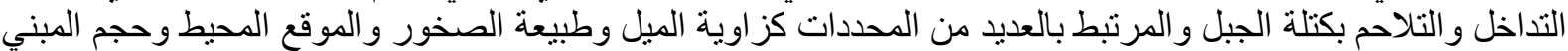
و الإرتفاع ،حيث سيتم إلقاء الضوء علي كيفية تعامل الإنسان مع الجبل أو الهضبة أو التل كمكان للإستيطان والمعيشة مع التيط

كلمات مفتاحية:البناء الجبلي ،الجبال، المرتفعات، تصنيف المباني الجبلية.

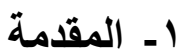

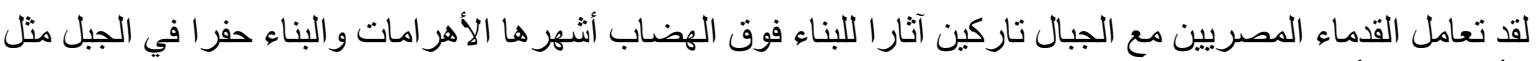

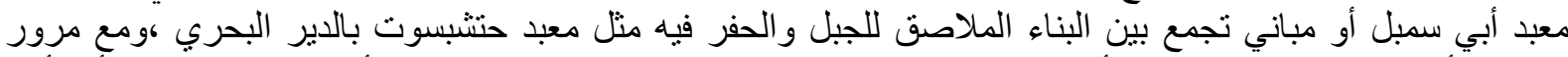

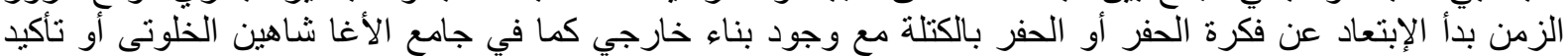

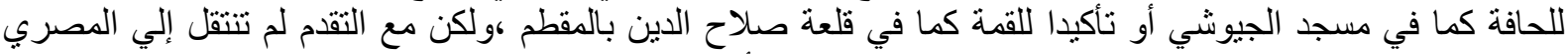

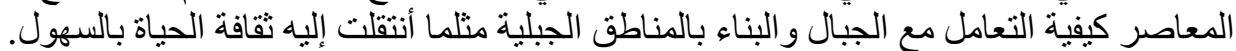

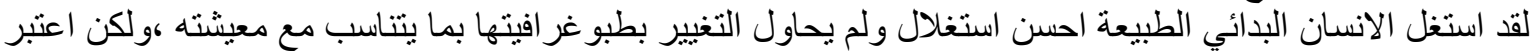

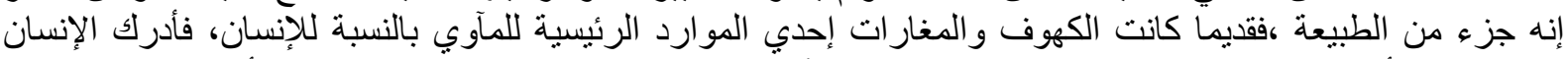

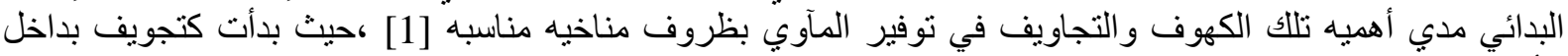

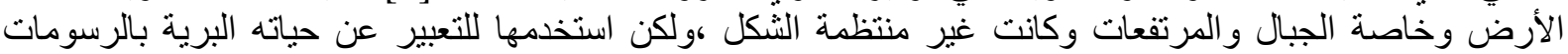

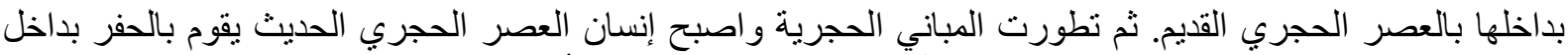

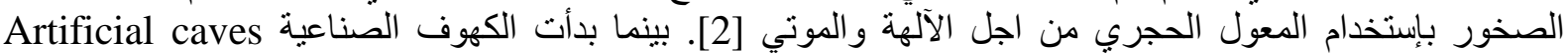

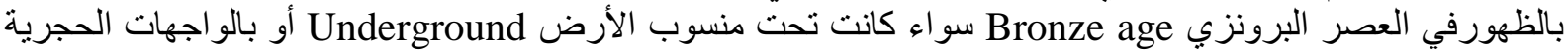
Rocky Fronts وتمت بإستخدام المعول المعدني [2]. إن المناطق المطله علي البحر الأبيض المتوسط من أوائل المناطق التي ظهرت بهان التها فكرة المآوي بالكهوف وتحت

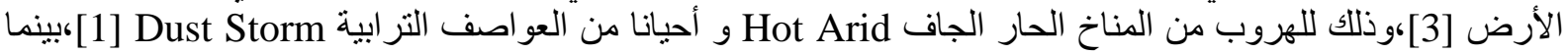

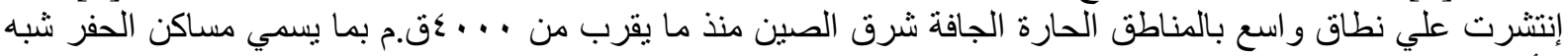

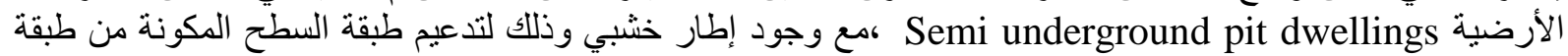

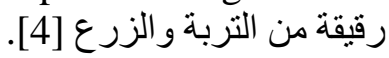

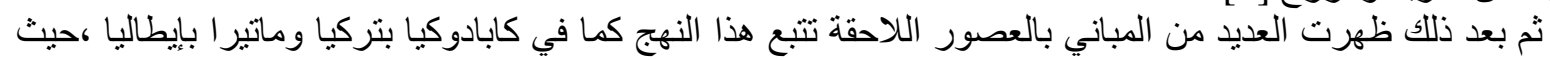

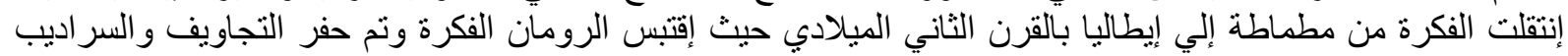
Grottoes \& Catacombs

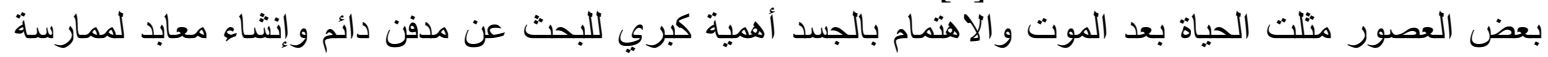

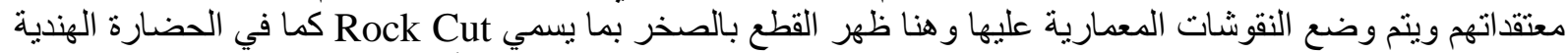

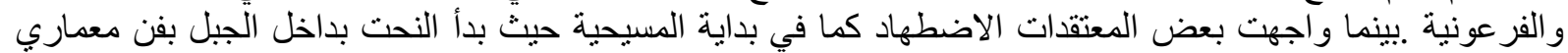

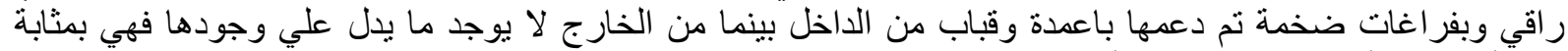

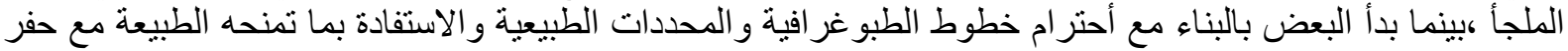

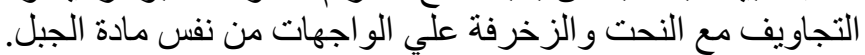

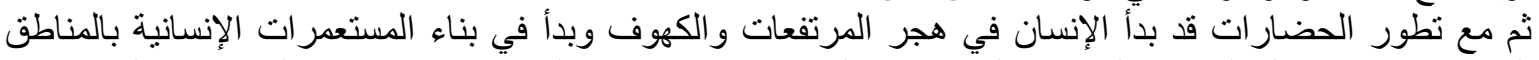

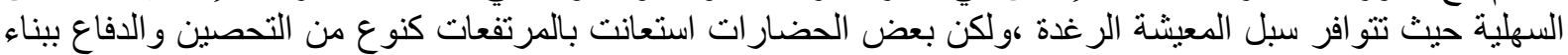

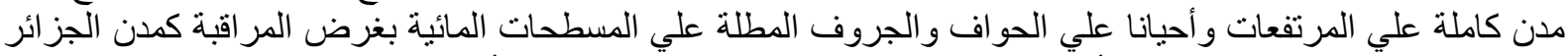

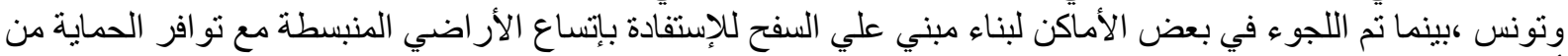

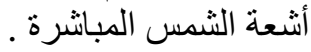

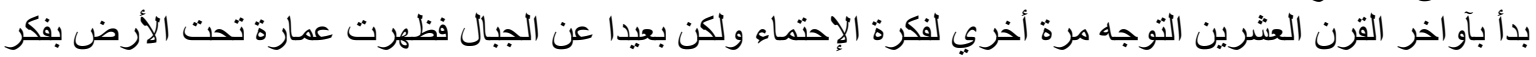

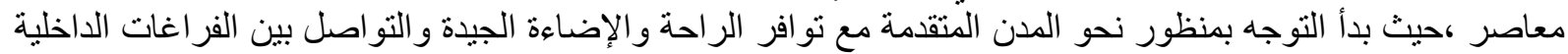

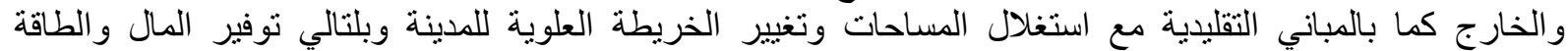

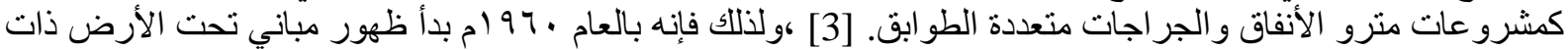

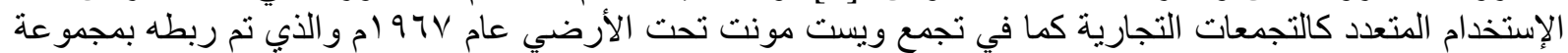


أنفاق إلي المدينة [3].

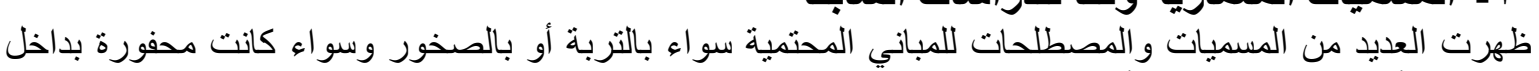

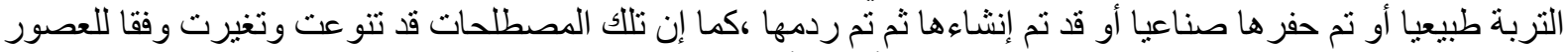

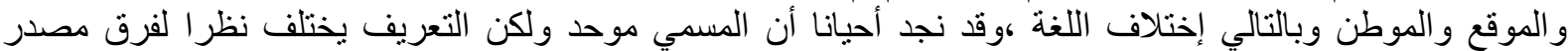

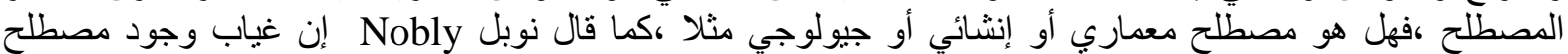

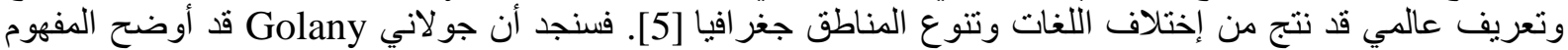

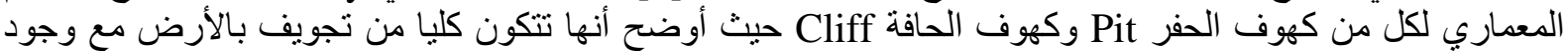

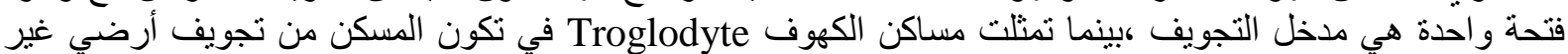

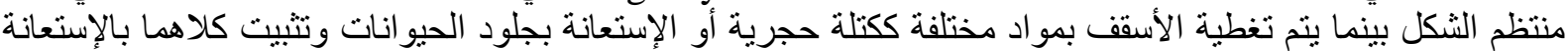

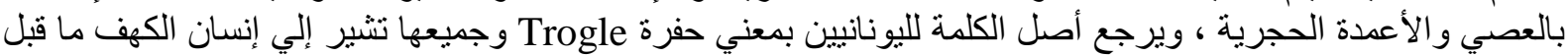

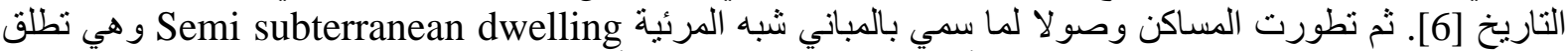

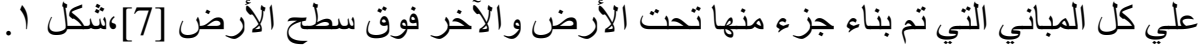
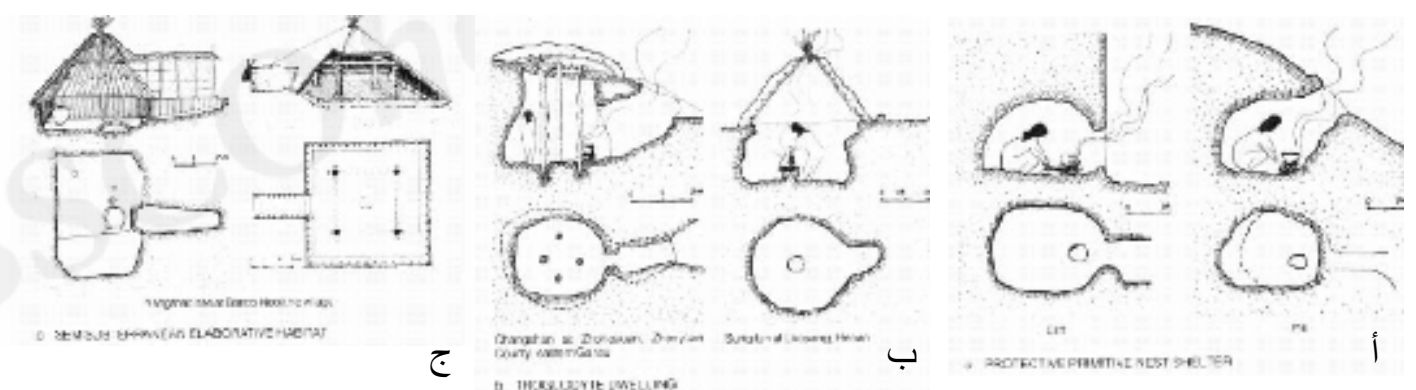

شكل 1. مراحل تطور البناء تحت الأرض ووصولا للأعلي منسوب الأرض [7]

يوضح نوبل Nobly أن التصنيفات المختلفة لعمارة المباني المحفورة Excavated dwellings غير كافية وغير

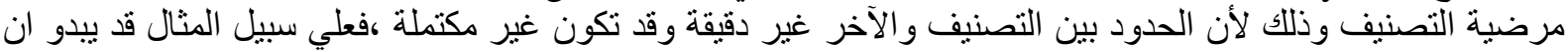

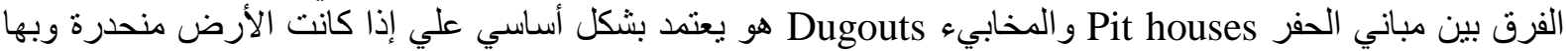

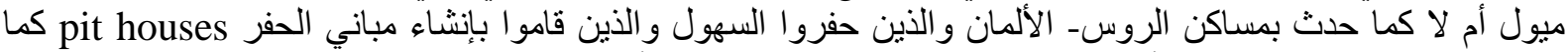

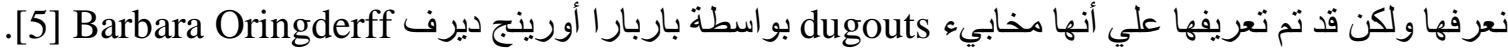

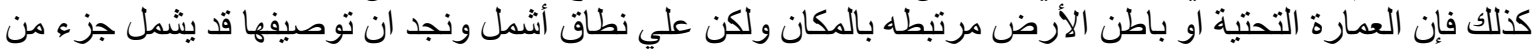

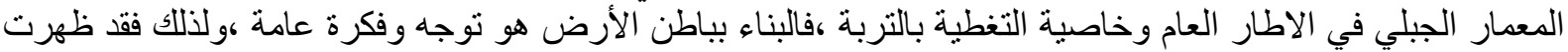

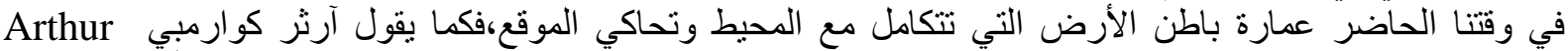
Quarmby

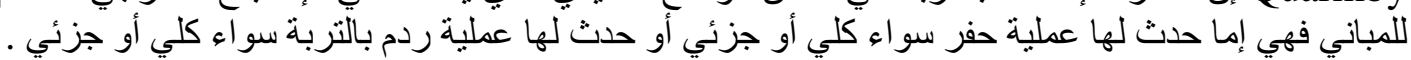

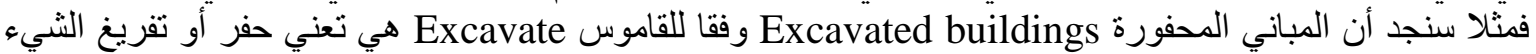

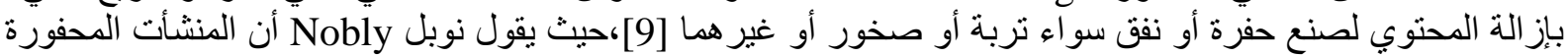
Excavated structures البعض أن المباني المحفورة تثمل مباني الحفر Pit houses ومباني الكهوف Cave dwellings [2]،بينما أوضح جو لاني Golany أن مباني الكهوف هي تشمل كل ما يتم حفرة بعمق تحت سطح الأرض بشكل عام سواء كانت حفر

Pأو كهوف حافية Pits Cliff

Y ـ ا التجاويف Subterranean

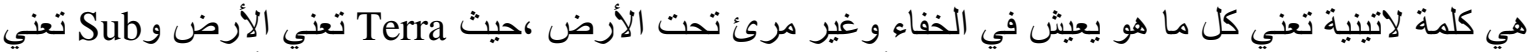

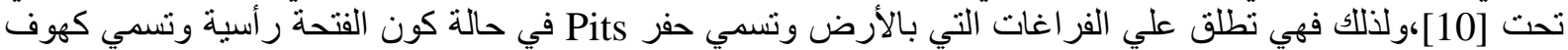

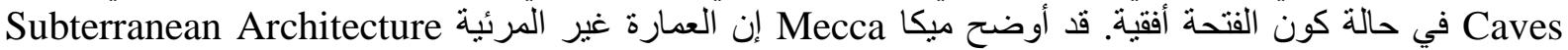
لاتقتصر علي المساكن المحلية ولكن تنوعت ما بين الأديرة والمخازن و المقابر و الملاجيء و والأنفاق مكونه مدن مجوفة المارية

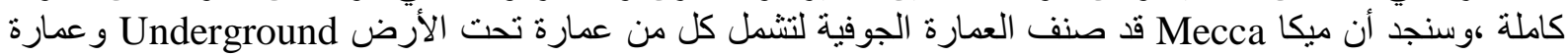

الكهوف Cave dwellings] 


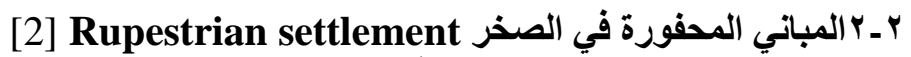

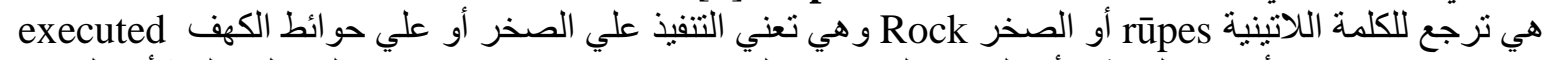

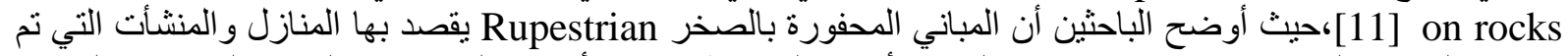

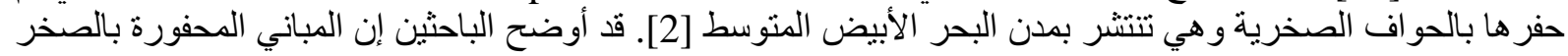

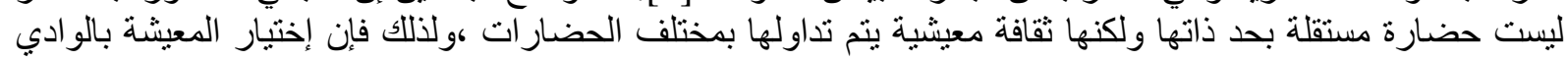

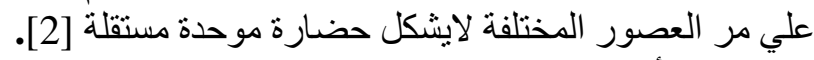

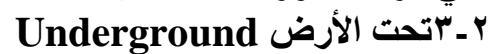

إن مفهوم تحت الارضي لارض Underground أرتبط بالرطوبة والاماكن المظلمة ولكن وفقا لقوانين البناء فإن البناء

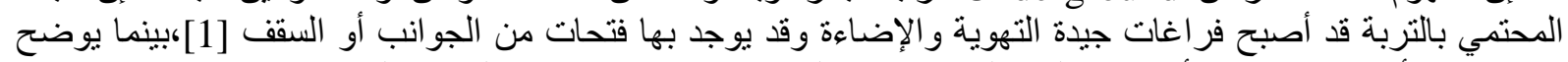

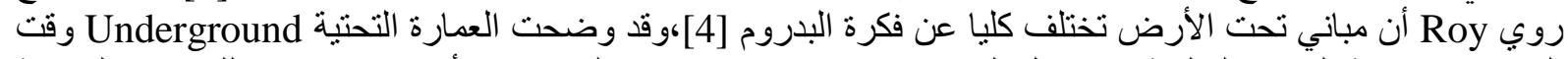

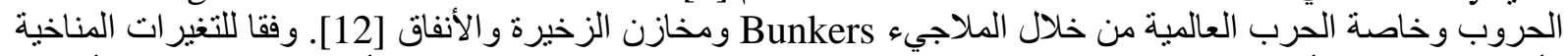

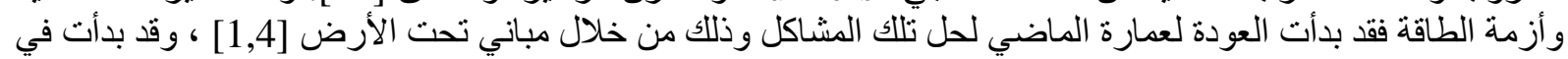

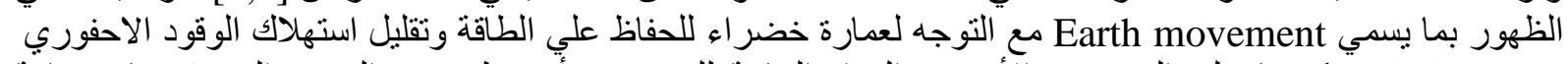

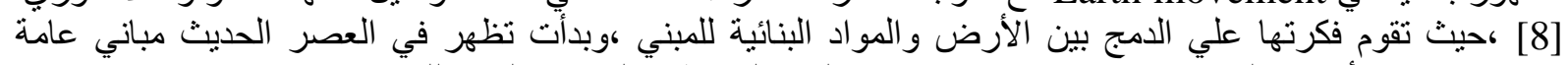

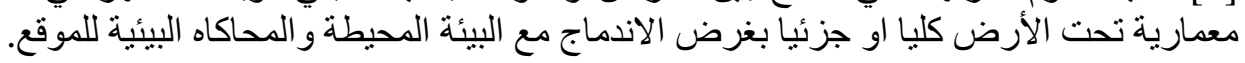

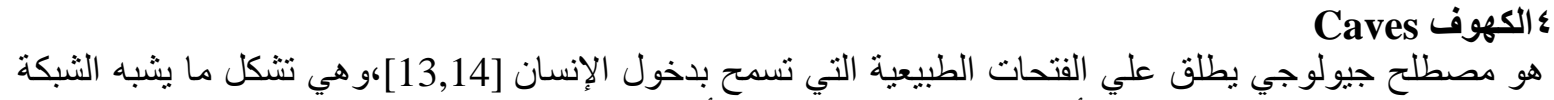

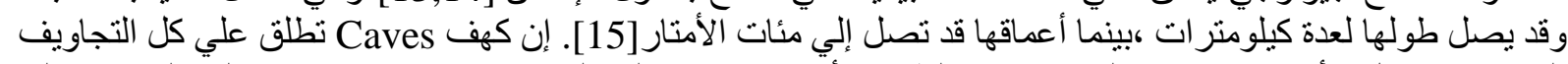

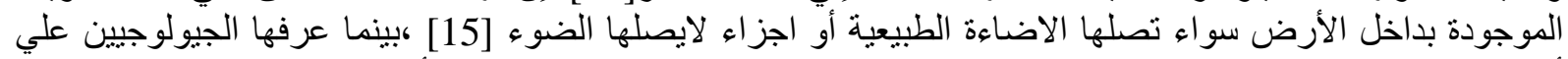

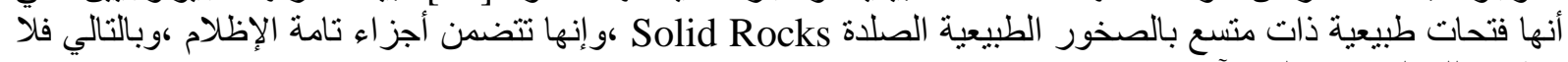

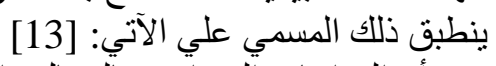

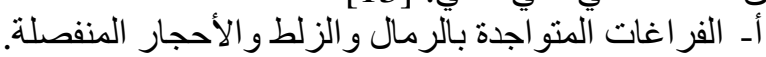

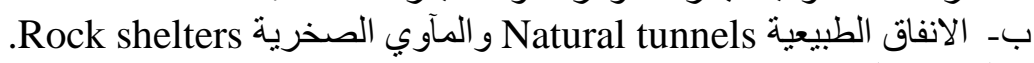
r _ ـ ـ ا الكهوف الطبيعية Natural Caves

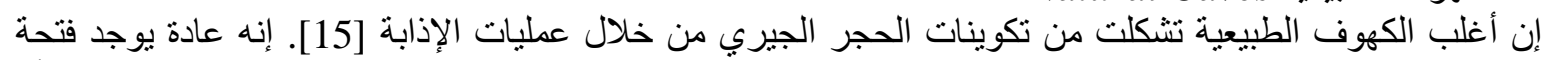

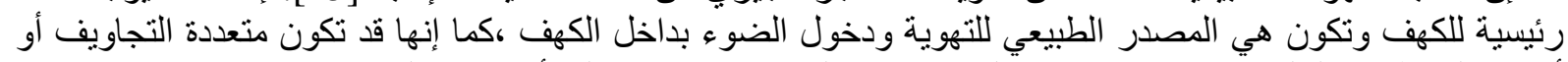

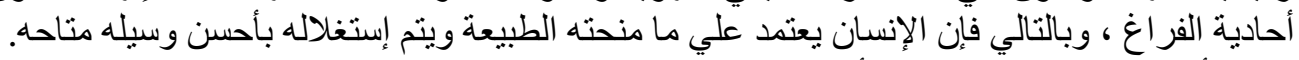

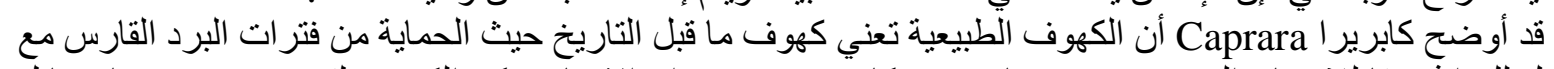

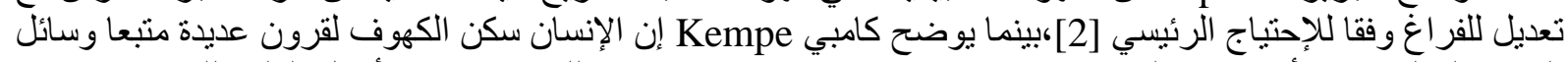

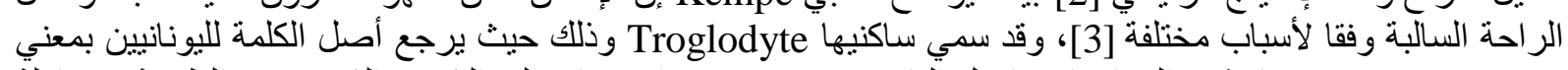

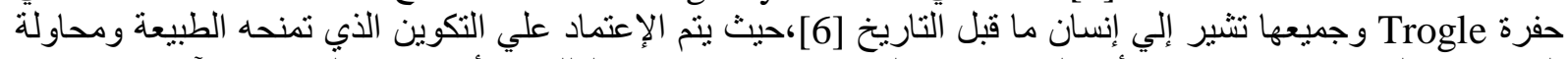

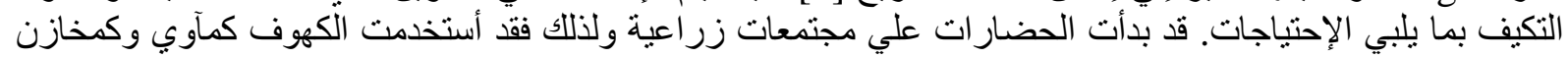

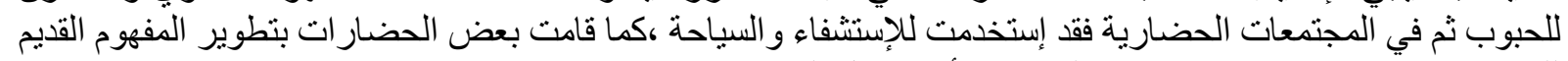

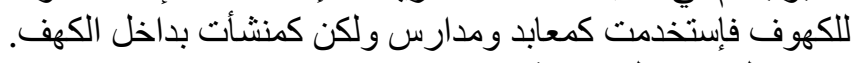

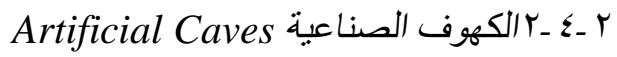

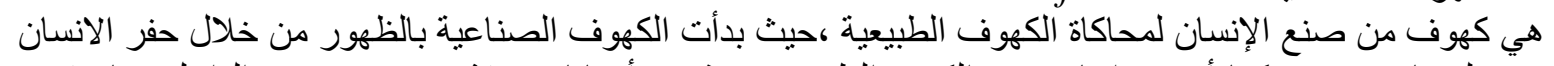

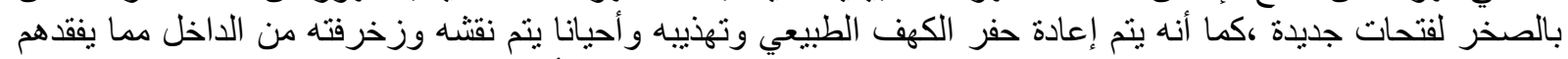

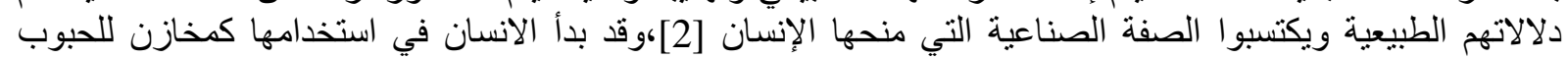

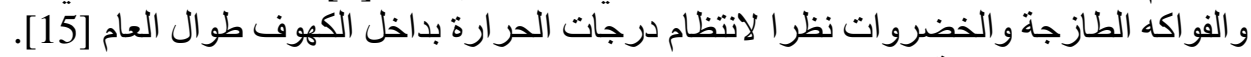

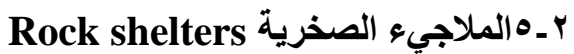

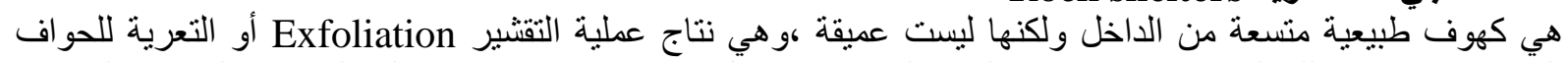

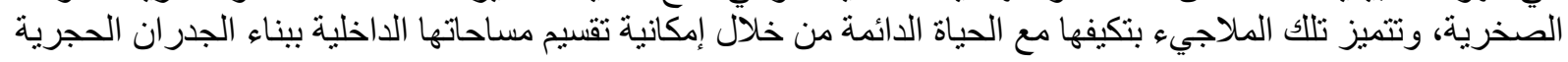

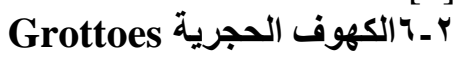

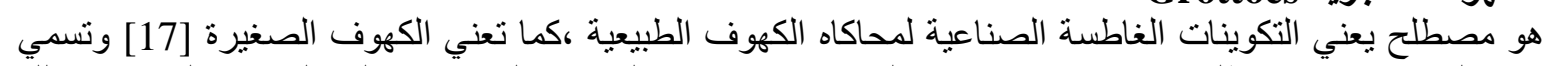

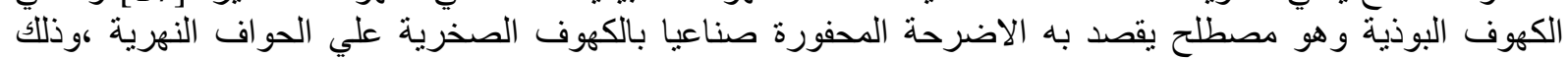

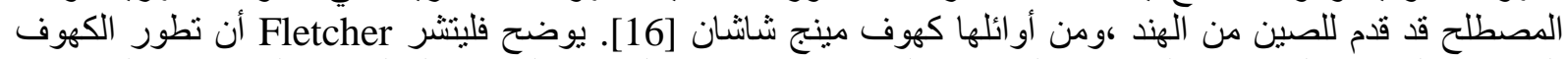

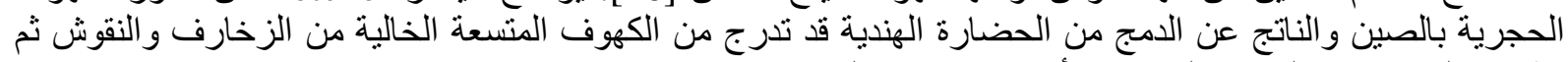

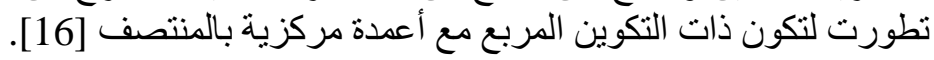




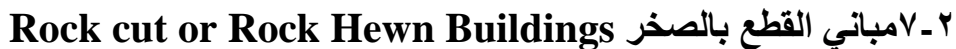

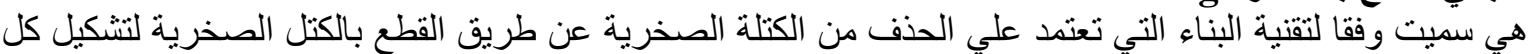

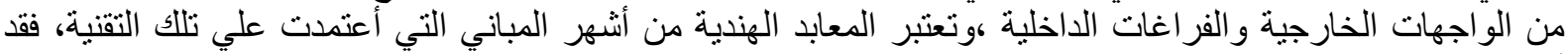

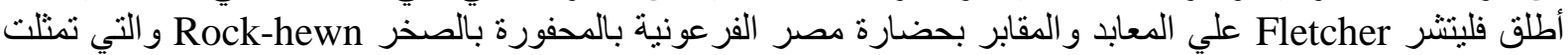

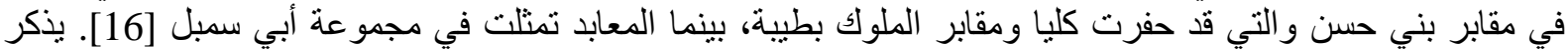

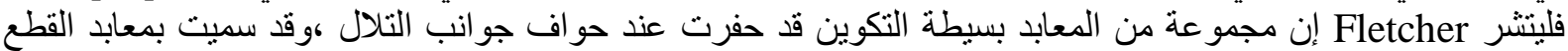
بالصخر Rock cut temples ويرجع تميز ها إلي إنه قد تم حفر ها من الداخل ونحت التماثيل بها وكذللك قد تم من الخارج

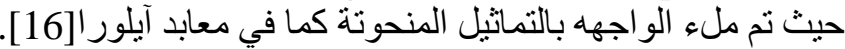

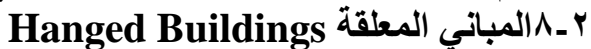

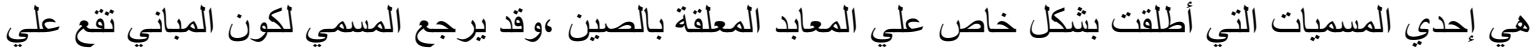

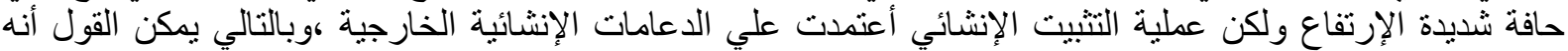

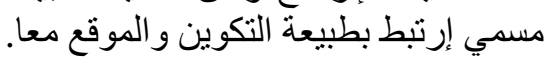

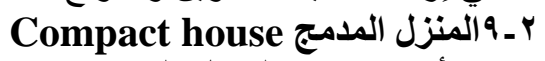
إن أهم ما يميز المنزي المنزل المدمج هو إنه يشغل مساحات محددة من الأر اضي ولذلك فهو يعتبر مثالي بالمناطق الجبلية

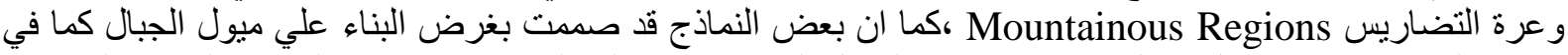

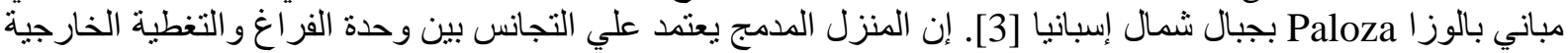

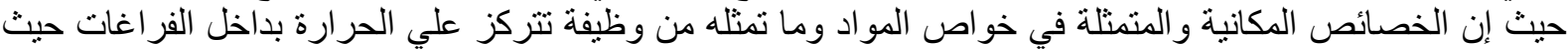

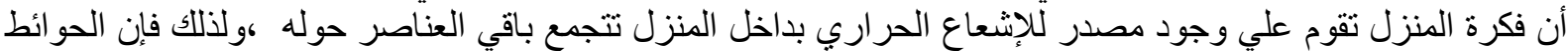

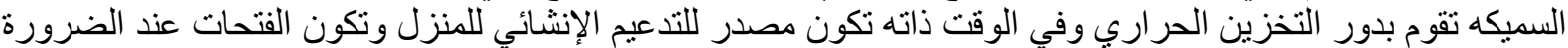

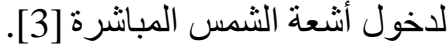

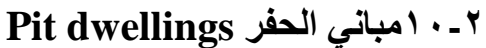
قد أوضح البعض أن مباني الحفر الكهفية Pit cave dwellings هي تللك التي تبني علي أر اضي منبسطة أوذات ميول

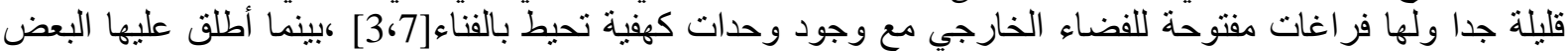

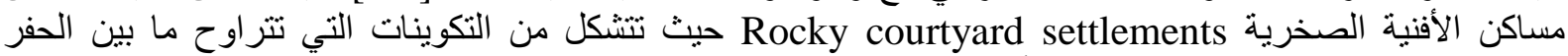

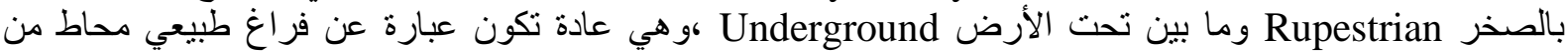

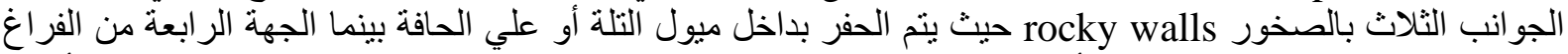

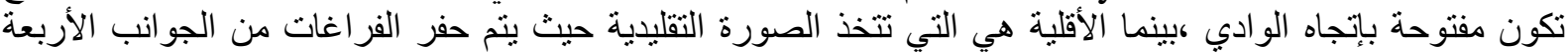

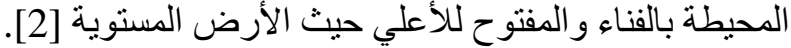

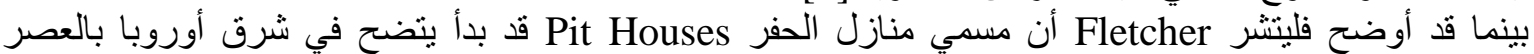

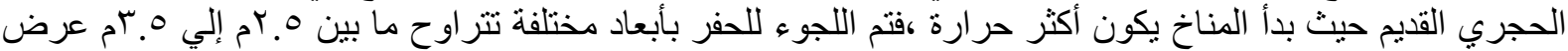

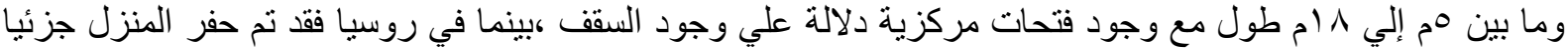

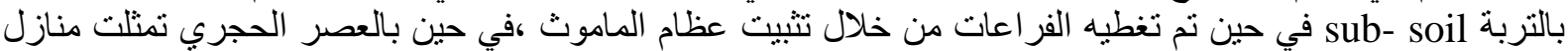

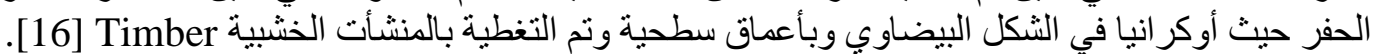

بـ الـ المباني الحواف أو الجروف:Cliff Buildings قد اوضتح البعض [7, 3 3 3 أن مباني الكهوف الحافية Cliff cave dwellings هي تلافك التي يتم حفر ها بالحواف

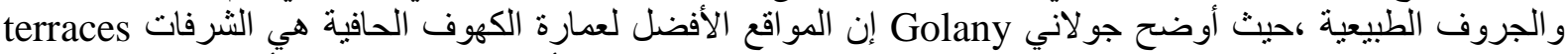

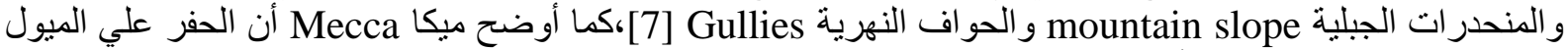

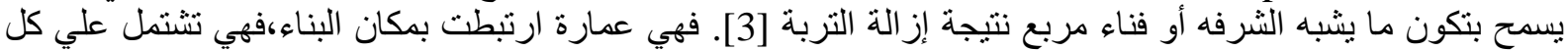

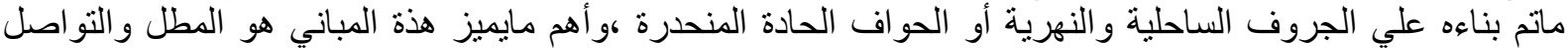
البصري و الذي اعتمد علي مدي إرتفاع الحافة والئي وموقع البناء بالنسبة لها.

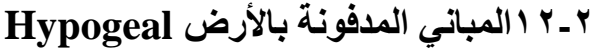

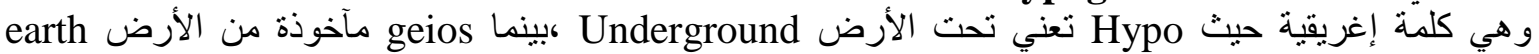

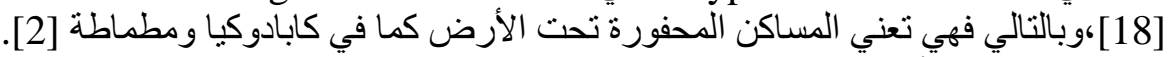

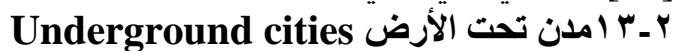

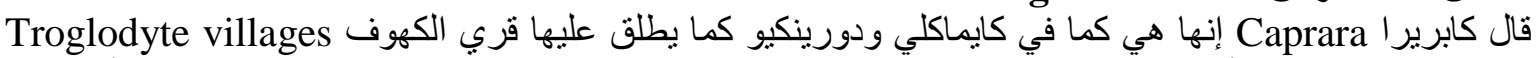

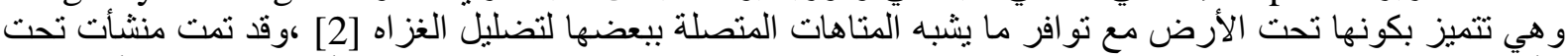

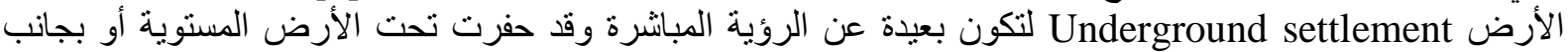

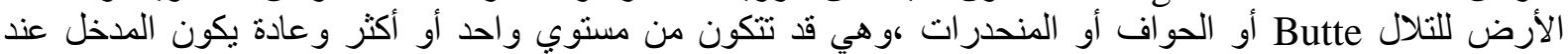

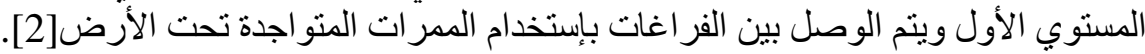




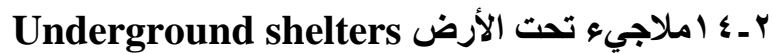

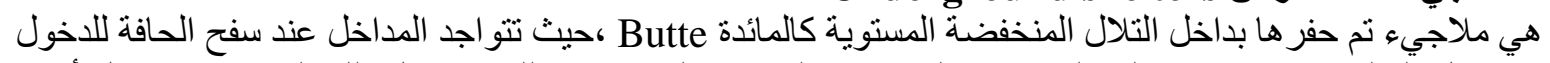

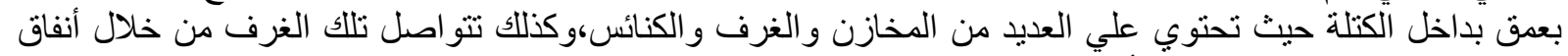

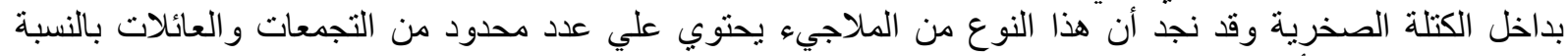

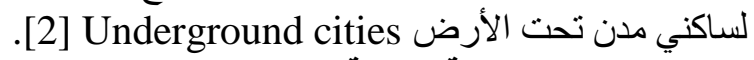

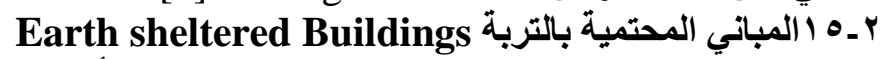

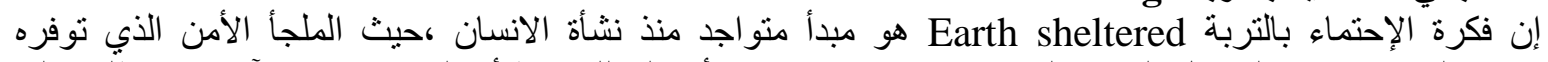

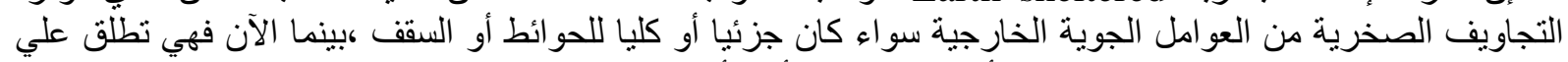

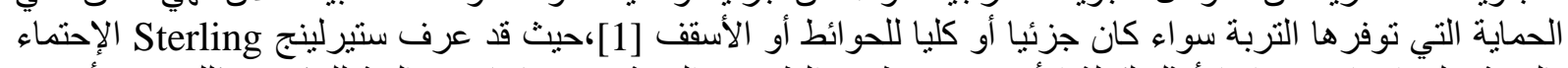

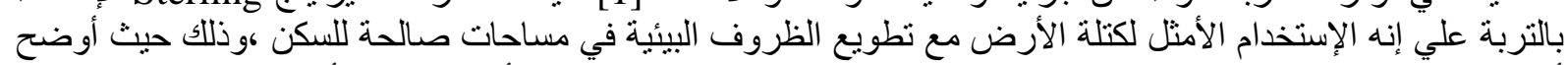

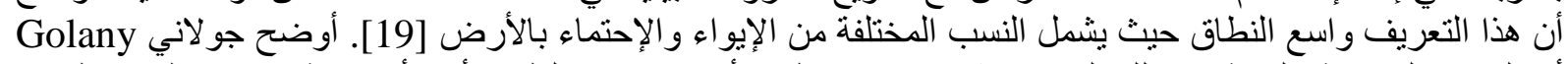

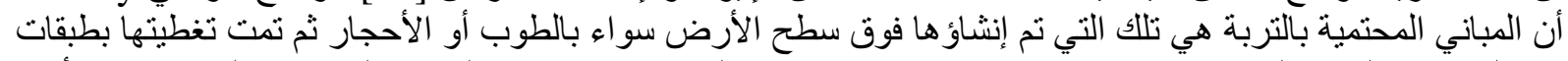

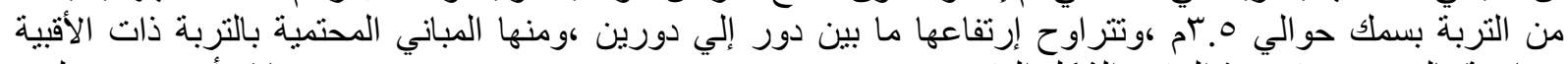

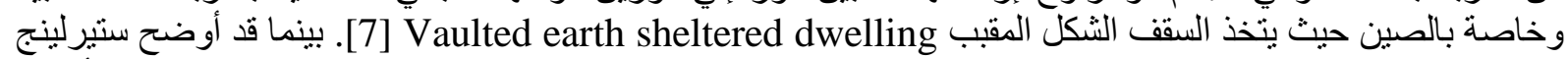

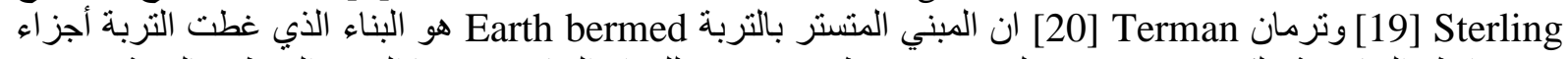

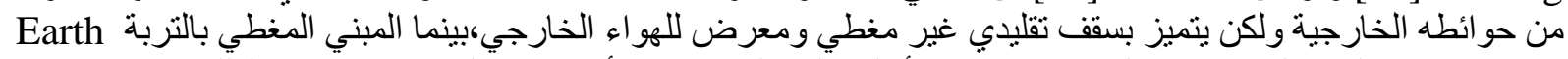

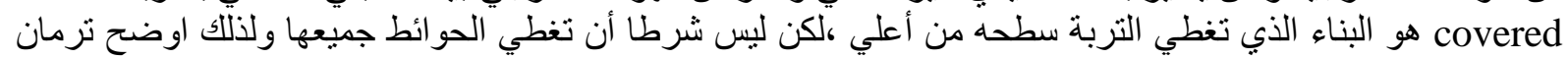
Terman

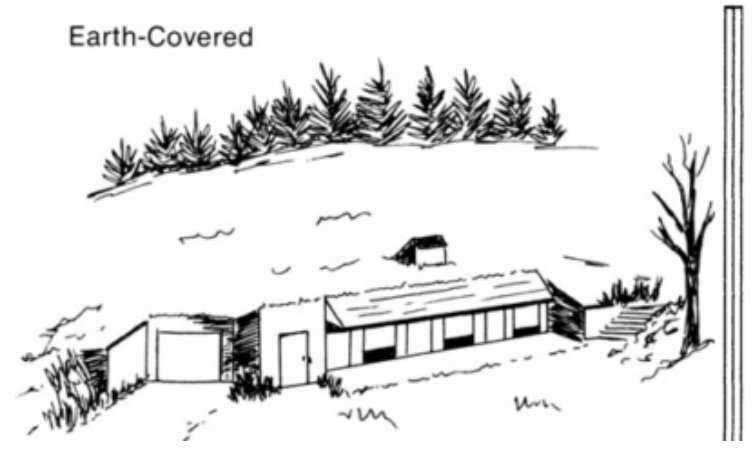

Earth-Bermed

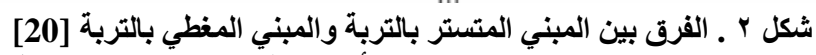

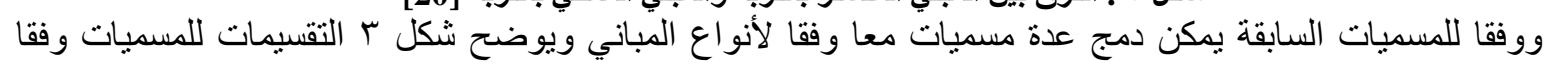

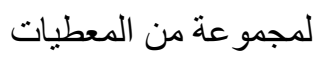

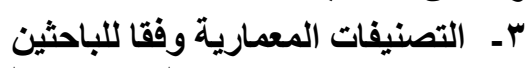

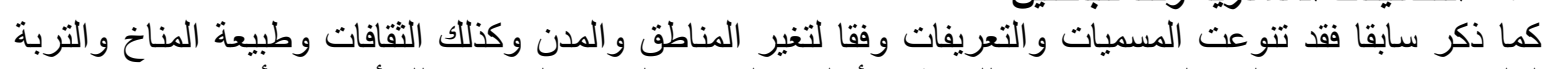

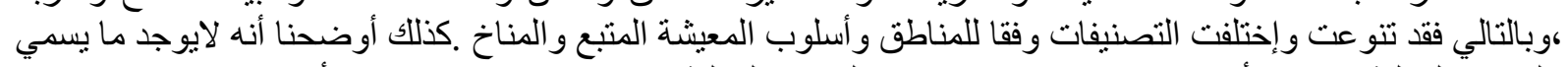

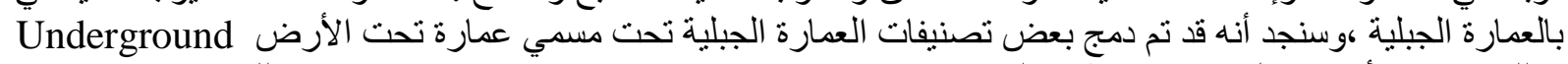

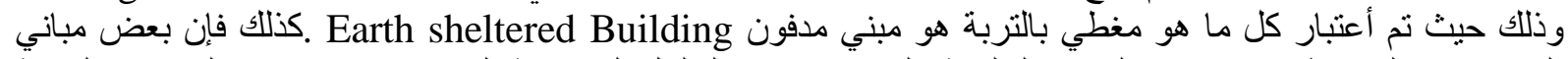

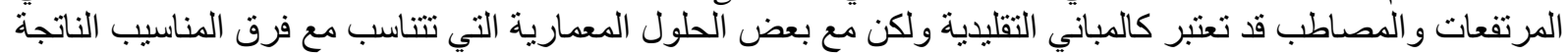

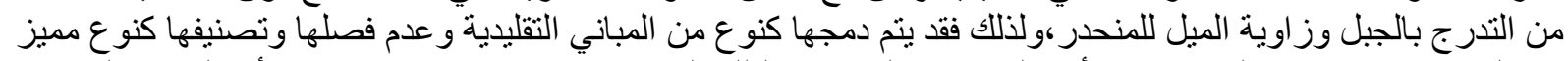

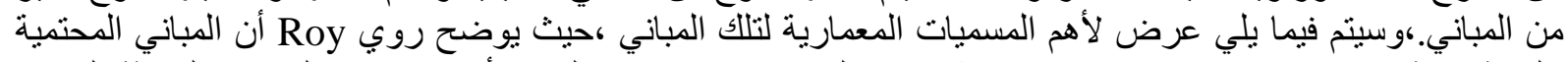

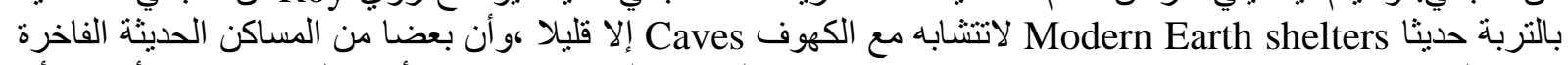

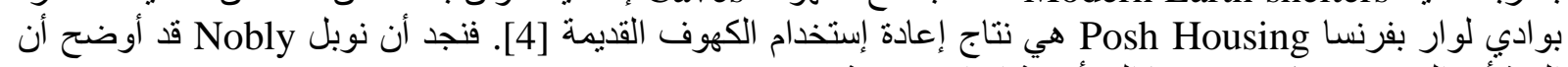

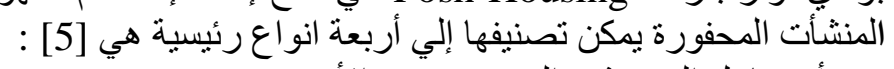

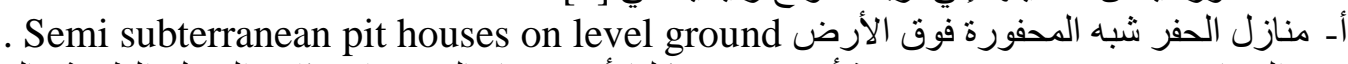
بـ المخابيء Dugouts : وهي منشأت محفورة كليا أو جزئيا بالمنحدرات ذات الميول المبات الطفيفة بالتربة المدموكة structures wholly or partially excavated in loosely compacted soil on gently sloping .land ج-مباني محفورة كليا تحت الأرض بالتربة اللينة .earth materials دـ الكهوف caves : وهي التكهفات الطبيعية بالصخور الصلبة ويتم توسيعها بو اسطة الإنسان. 


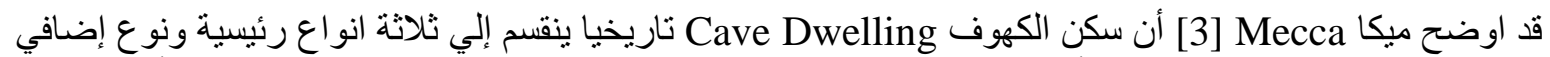

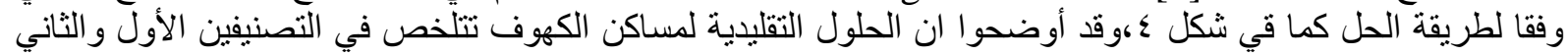

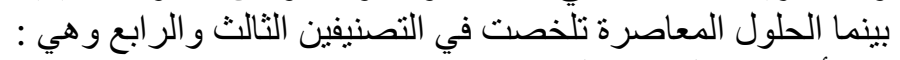

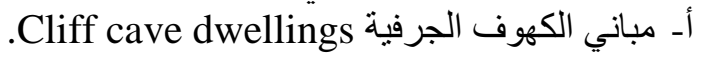

ب- باني الحفر الكهفية Pit cave dwellings.

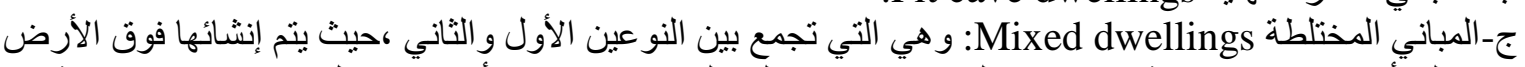

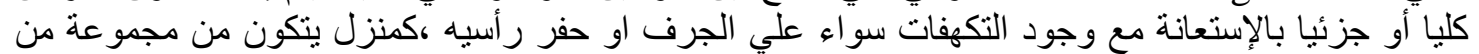

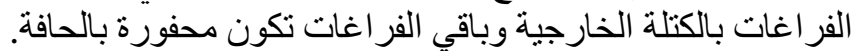
دـ الحلول الهجينة Hybrid :وهي تتمثل في المباني المحتمية بالتربة Earth Sheltered ،حيث تكون الوحدة مبنية 


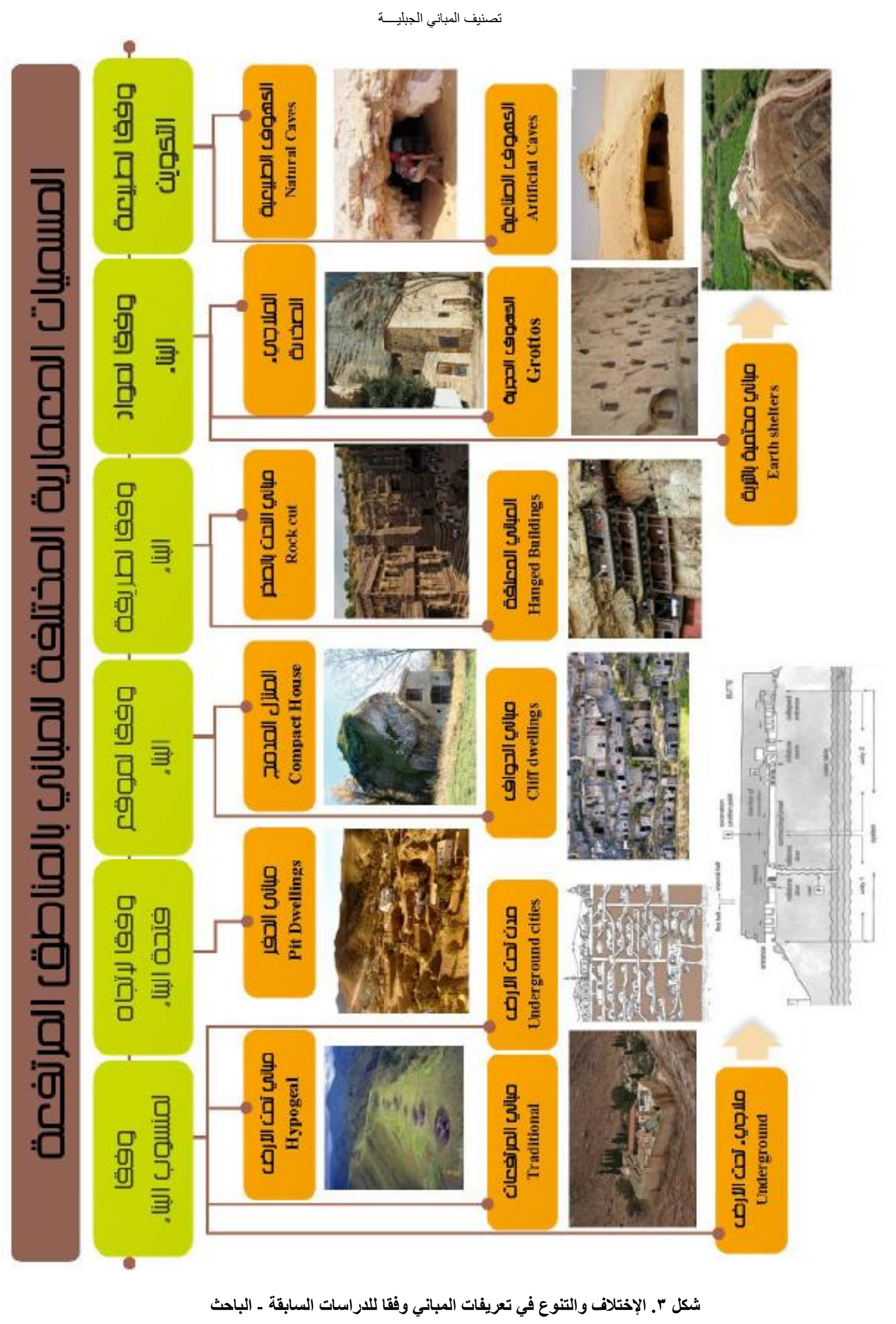




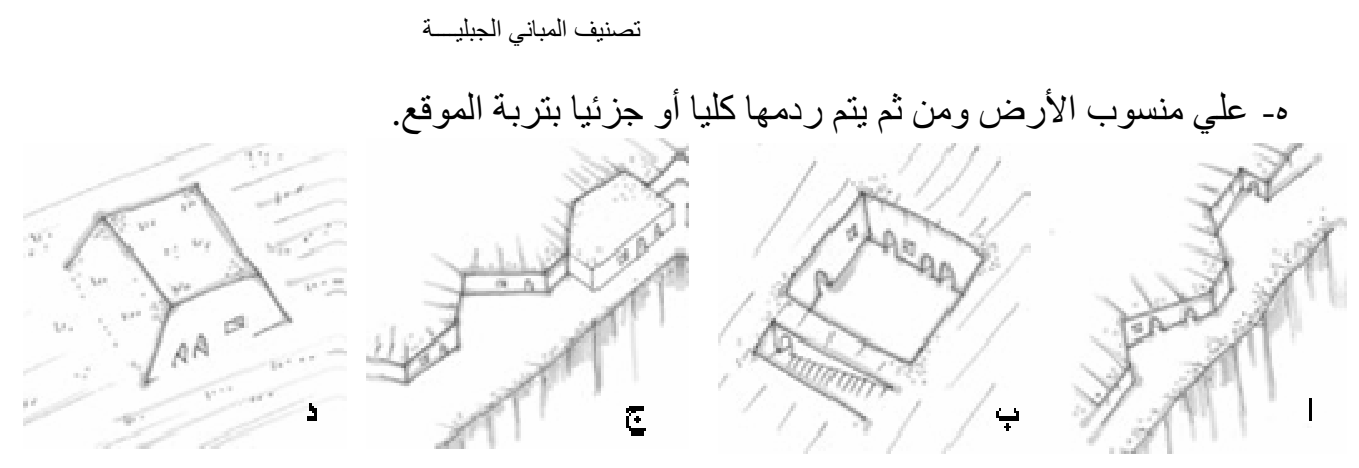

[3] شكل ؛. أنواع مباني الكهوف المختلفة

وبالتصنيف السابق نجد أن التصنيف و الذي سمي بمباني الكهوف Cave Dwellings قد إنتمل علي المباني المحتمية

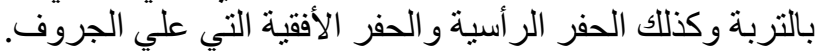

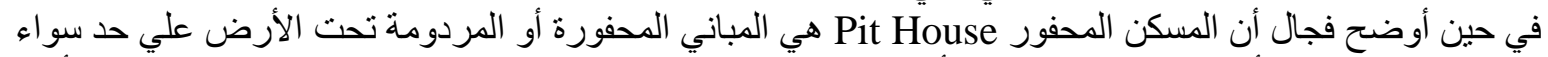

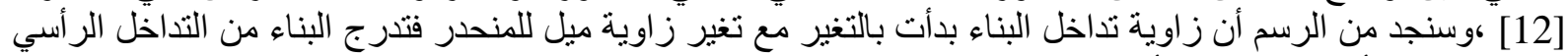

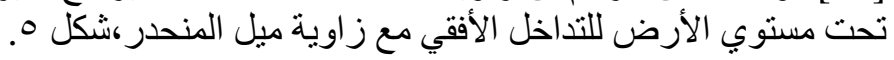

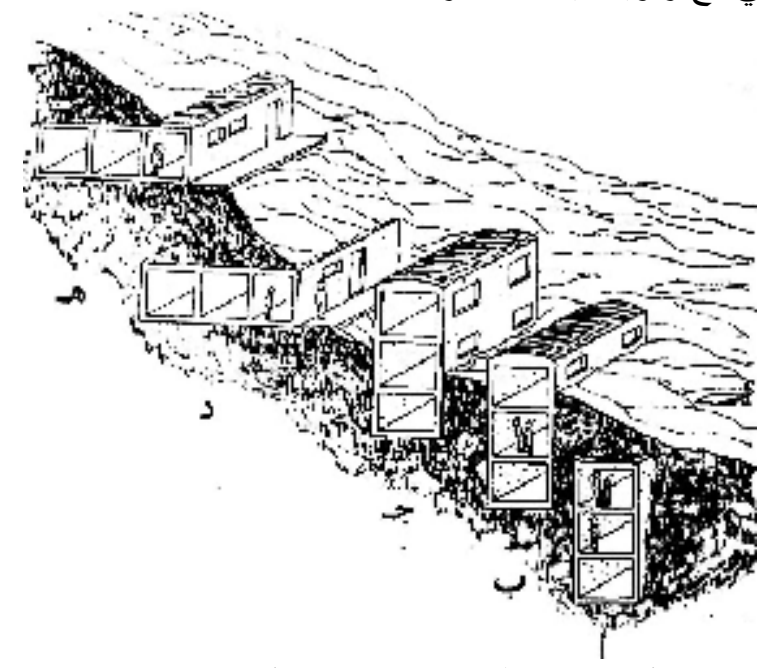

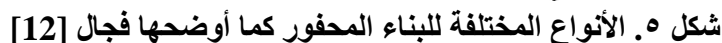

قد قام كابرير ا Caprara بتقسيم مباني الحفر بالصخور Rupestrian Settlement وفقا للإستخدام و الموقع إلي:[2] أـ الكهوف الطبيعية Natural Caves

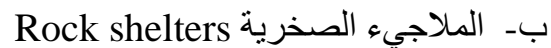

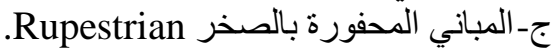

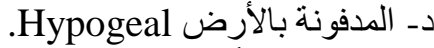

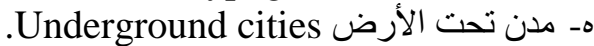

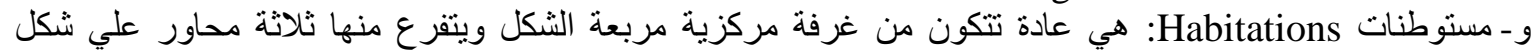

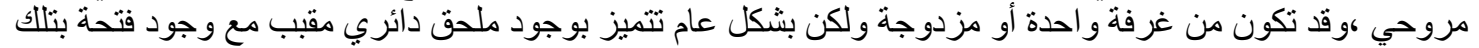

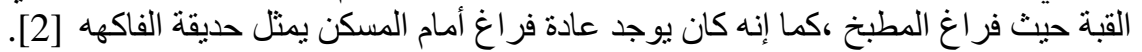

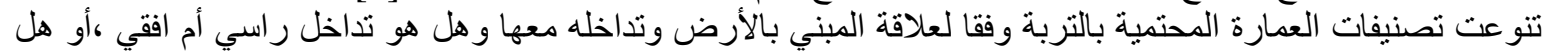

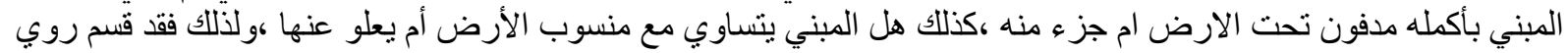

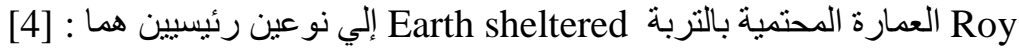
أـ تحت الأرض كليا Chambered) Truly underground) : حيث أن المنثأ والإنثاء الداخلي ينو اجد كليا تحت

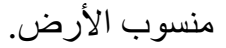
بـ تحت الأرض جزئيا Bearming) Mounding earth against the side wall):حيث أن إنشائي المبني علي منسوب الأرض أو أعلي منها بقليل.

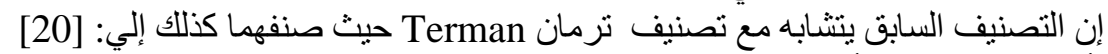

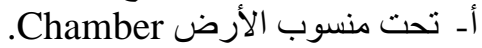

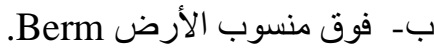
كما قام ترمان Terman كذللك بتصنيف المباني وفقا لطبيعة التداخل مع الأرض ،شكل 7. 


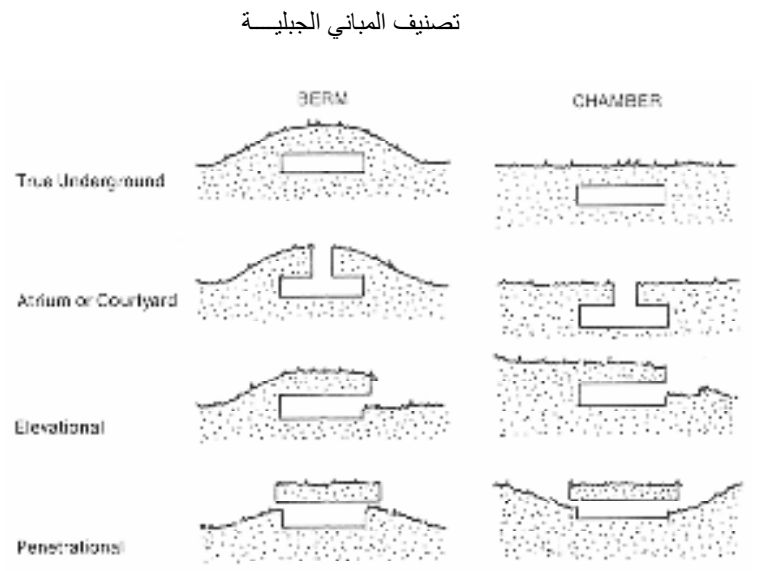

شكل 7 ـ تصنيف المباني المحتمية بالتربة Earth sheltered ]

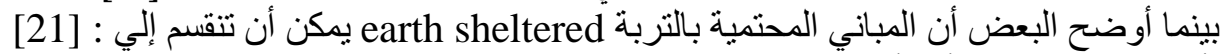

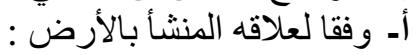

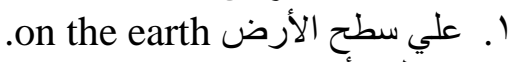

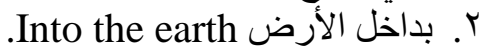
ب- و وققا لمعطيات الموقع وتصميم المسقط الأفقي:

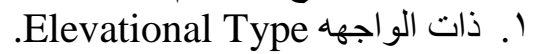
r. آ. ذات الفناء الداخلي Atrium Type.

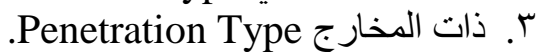

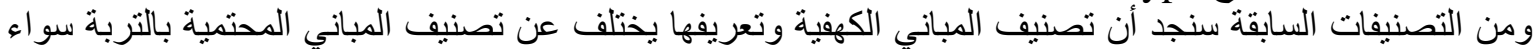

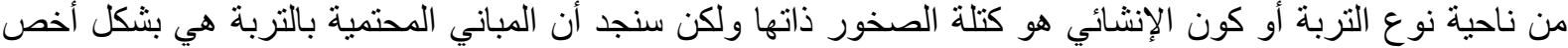

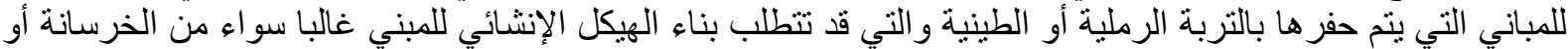

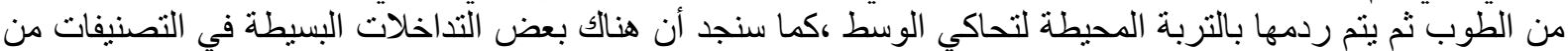

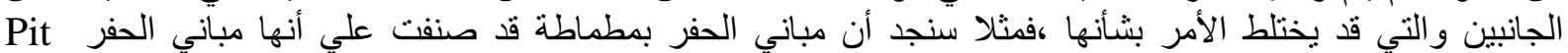

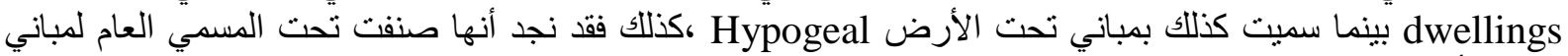

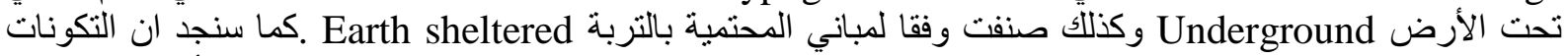
المخروطية بكابادوكيا قد صنفت علي انها مباني كهفبة حافية Cliff cave dwellings وكذللك صنفت بأنها من المباني

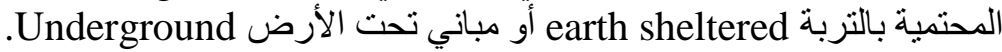

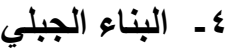

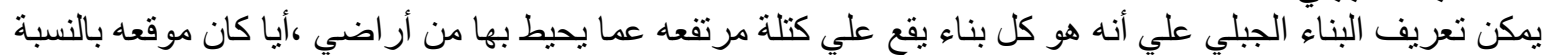

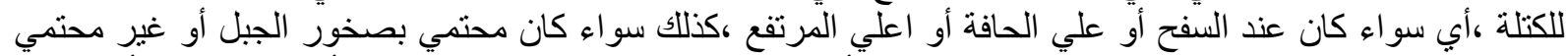

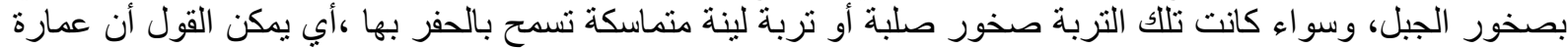

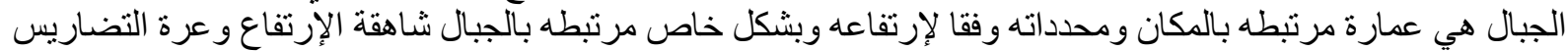

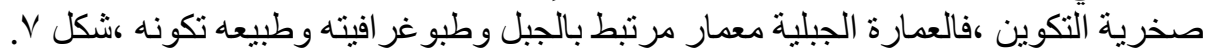
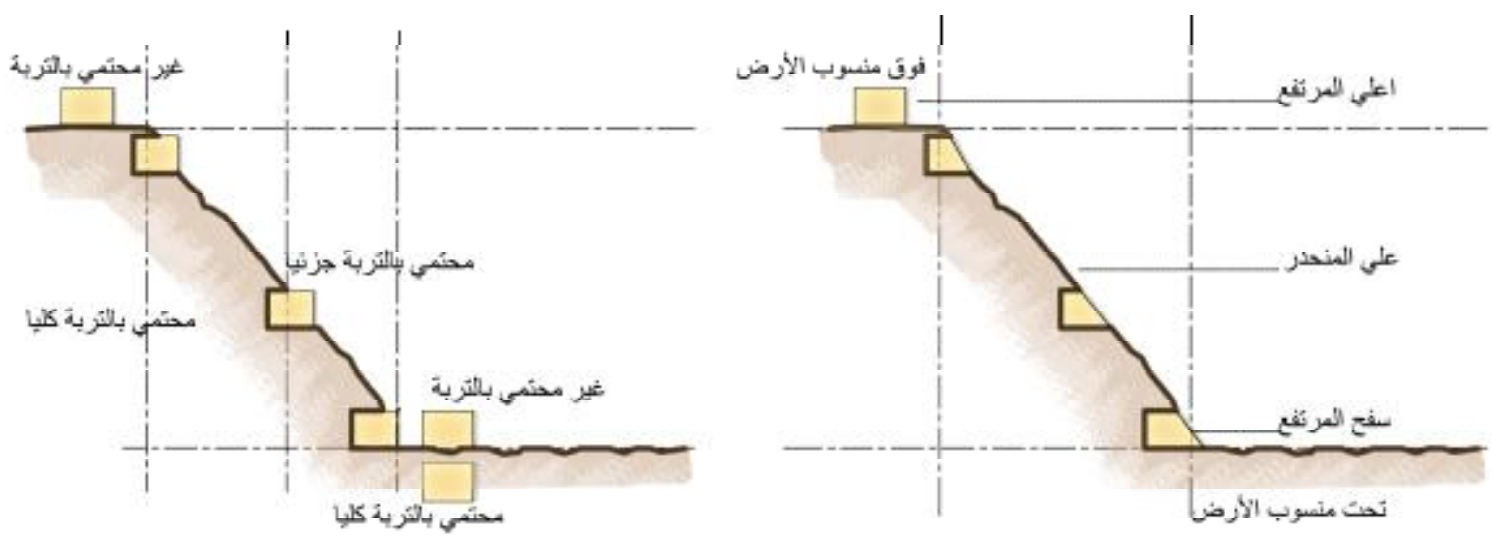

شكل V. مفهوم البناء الجبلي - الباحث

بالجزء السابق قد تم عرض مجموعة من التعريفات والتصنيفات التي إرتبطت بفكرة البناء بالمناطق المرتفعة أو البناء 


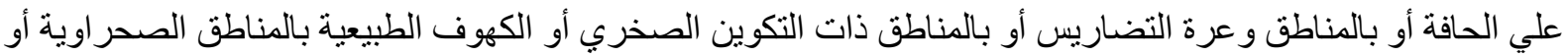

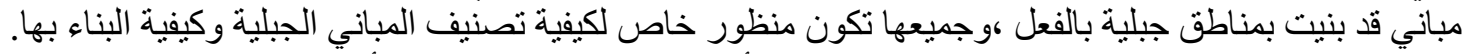

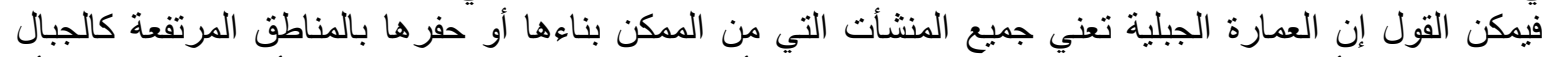

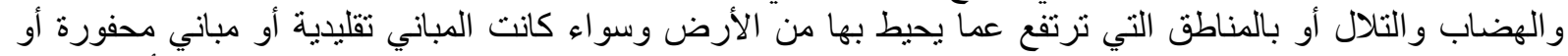
مباني محتمبة بالتربة ،ولذللك فإنه سيتم تصنيف النماذج المختلفة للتعمارة الجبلية وفقا لمجمو عة من المحددات والأبعاد.

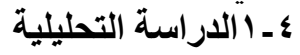

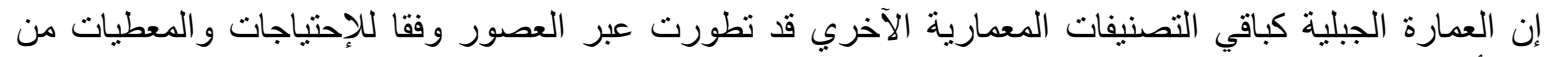

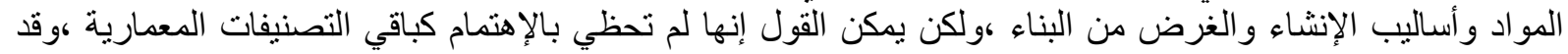

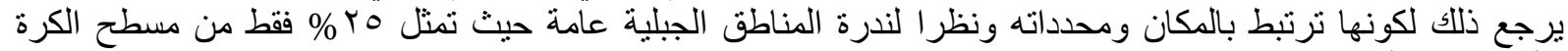

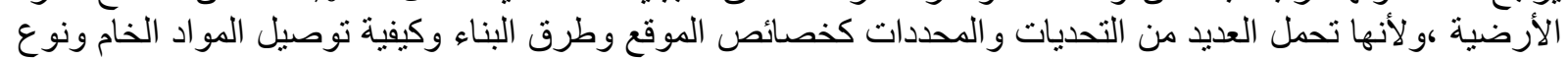

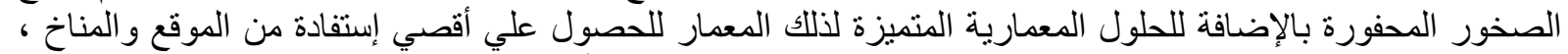

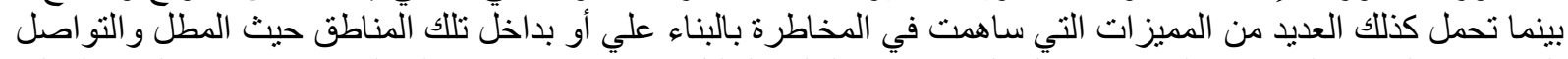

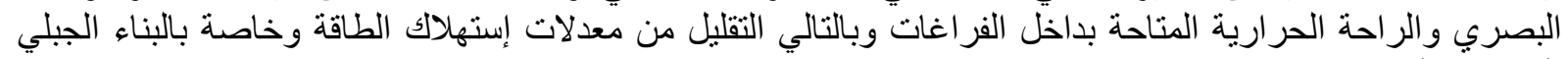
المحتمي بالتربة. ولذللك فإن الدر اسة التحليلية قد إرتكزت علي العلاقة بين الجبل أو المرتفع و البناء وتحليليها من نواحي متعددة بما يسمح

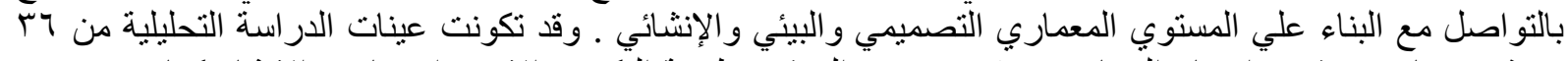
نموذج معماري ،وقد ثم اختيار العينات بحيث تثتوع في الموقع وطبيعة التكون و الإستخدام وتاريخ الإنشاء كما هو موضح

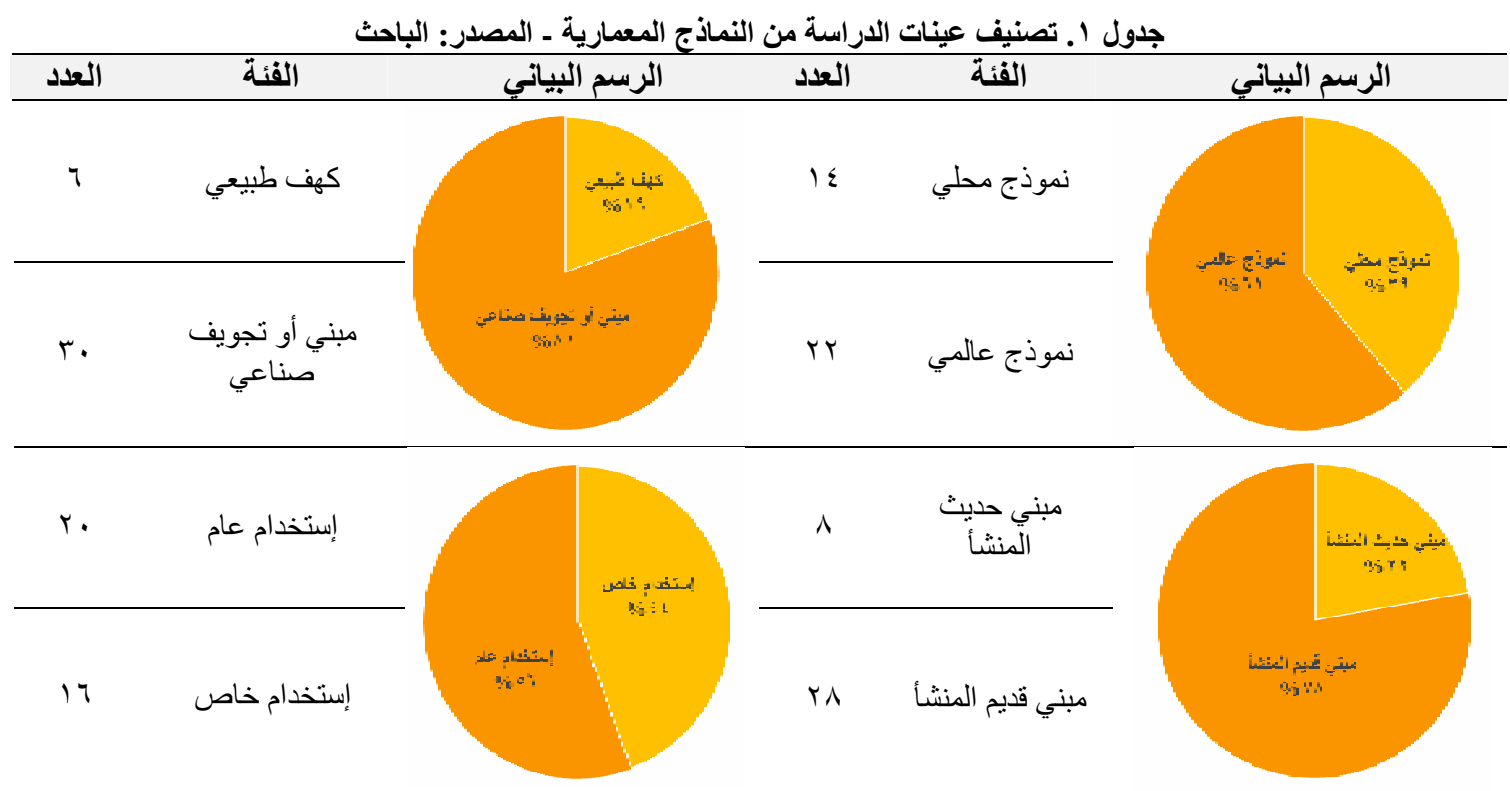

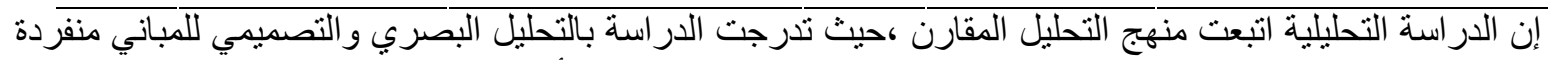

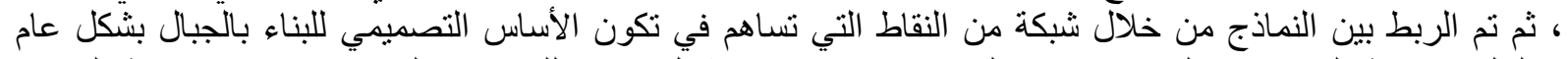

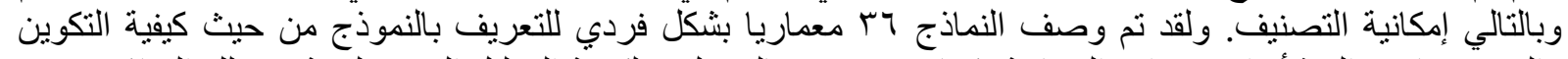

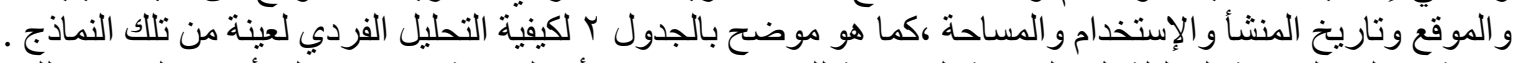

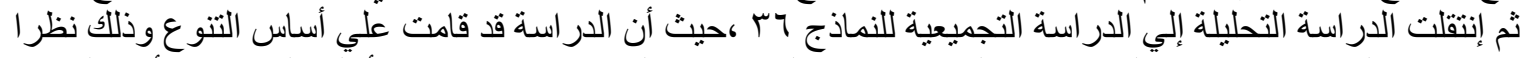

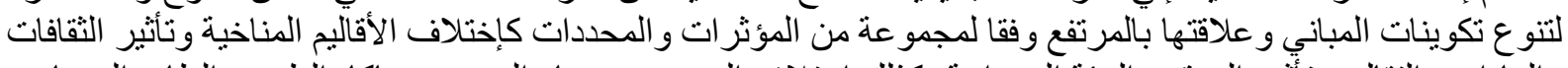

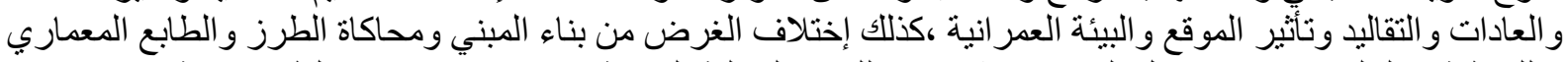

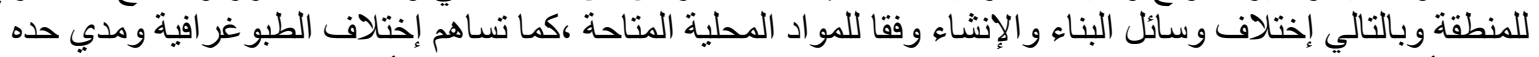

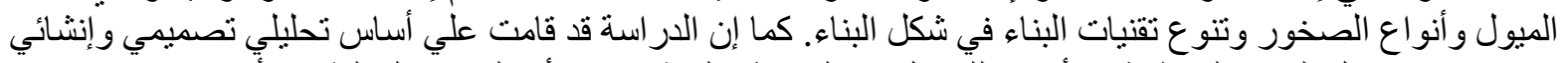

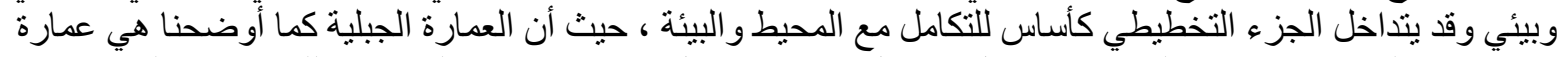

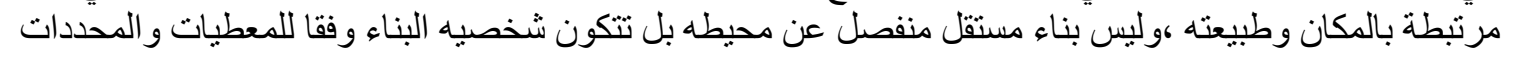

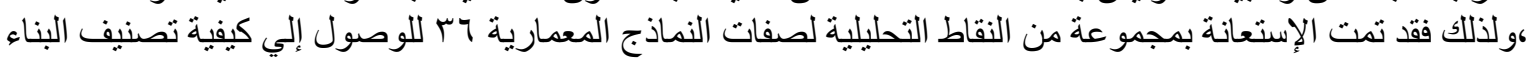

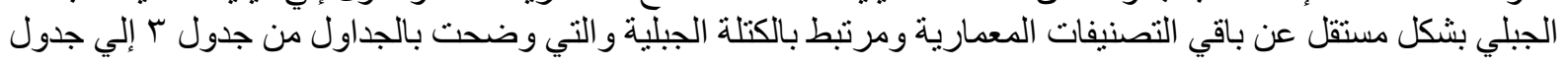


•.جدول r التحليل الفردي للنماذج المعمارية محل الدراسة

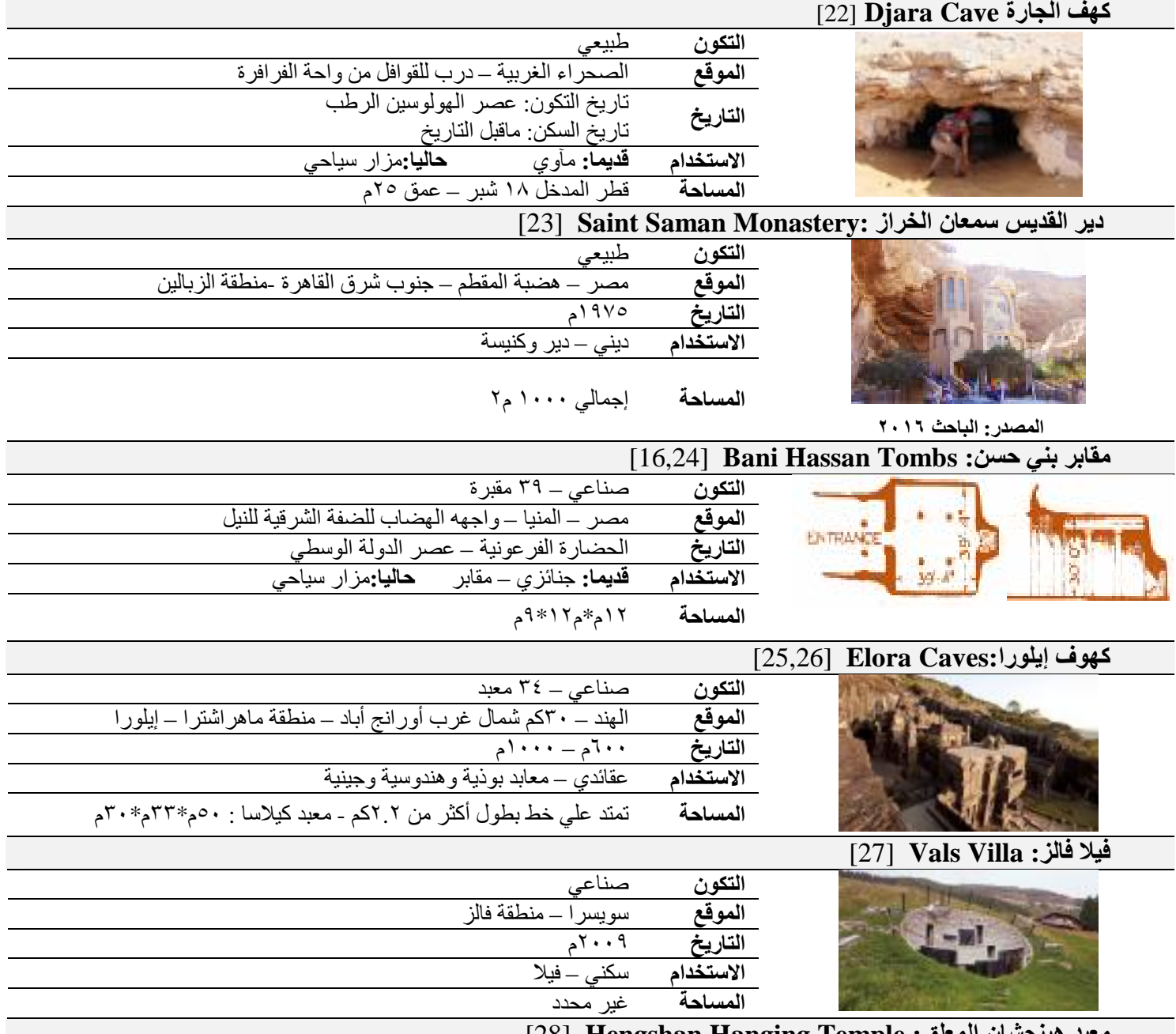

معبد هينجشان المعلق: Hengshan Hanging Temple [28

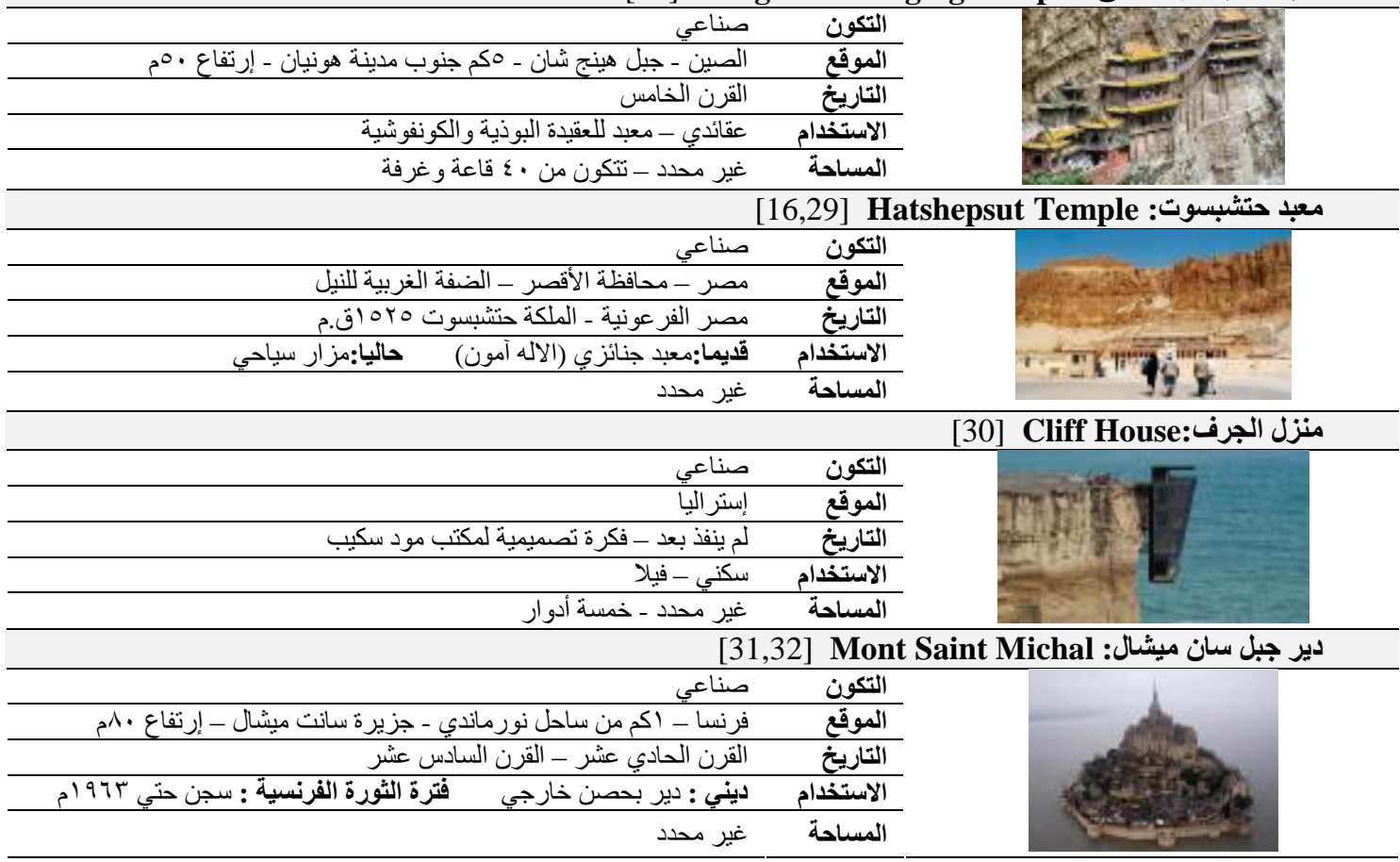


جدول r. الجوانب التحليلية للنماذج المعمارية المختلفة (1) ـ المصدر: الباحث

\begin{tabular}{|c|c|c|c|c|c|c|c|c|c|c|c|c|}
\hline 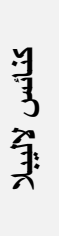 & 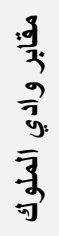 & $\begin{array}{l}y \\
\text { ż. } \\
\text { y. }\end{array}$ & $\begin{array}{l}3 \\
3 \\
3 \\
3 \\
3 \\
3\end{array}$ & 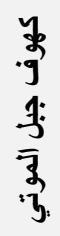 & 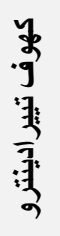 & 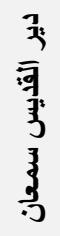 & 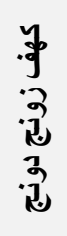 & $\begin{array}{l}.9 \\
\frac{9}{3} \\
3 \\
3\end{array}$ & 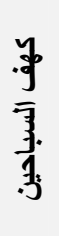 & 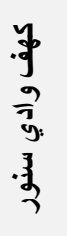 & $\frac{.7}{\overline{7}}$ & سمات النماذج المعمارية \\
\hline & & & & & & $\sqrt{ }$ & $\sqrt{ }$ & $\sqrt{ }$ & $\sqrt{ }$ & $\sqrt{ }$ & $\sqrt{ }$ & طبيعة التكون \\
\hline$\sqrt{ }$ & $\sqrt{ }$ & $\sqrt{ }$ & $\sqrt{ }$ & $\sqrt{ }$ & $\sqrt{ }$ & & & & & & & صناعي \\
\hline$\sqrt{ }$ & & $\sqrt{ }$ & $\sqrt{ }$ & $\sqrt{ }$ & & $\sqrt{ }$ & $\sqrt{ }$ & & $\sqrt{ }$ & v & $\sqrt{ }$ & أفقي \\
\hline \multirow[t]{3}{*}{$\sqrt{ }$} & & $\sqrt{ }$ & & $\sqrt{ }$ & $\sqrt{ }$ & & & & & & & اتحاه التـاذل \\
\hline & $\sqrt{ }$ & & & & & & & $\sqrt{ }$ & & & & إنجاه الشاحل \\
\hline & & & & & & & & & & & & 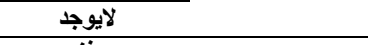 \\
\hline \multirow[t]{2}{*}{$\sqrt{ }$} & $\sqrt{ }$ & $\sqrt{ }$ & $\sqrt{ }$ & v & $\sqrt{ }$ & & & $\sqrt{ }$ & $\sqrt{ }$ & $\sqrt{ }$ & $\sqrt{ }$ & حذف ( ح \\
\hline & & & & & & $\sqrt{ }$ & $\sqrt{ }$ & & & & & 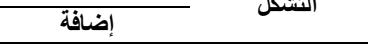 \\
\hline \multirow[t]{4}{*}{$\sqrt{ }$} & $\sqrt{ }$ & $\sqrt{ }$ & $\sqrt{ }$ & $\sqrt{ }$ & $\sqrt{ }$ & & $\sqrt{ }$ & $\sqrt{ }$ & $\sqrt{ }$ & $\sqrt{ }$ & $\sqrt{ }$ & 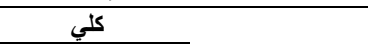 \\
\hline & & & & & & $\sqrt{ }$ & & & & & & عمق التلدل \\
\hline & & & & & & & & & & & & لايوجذ \\
\hline & $\sqrt{ }$ & & & & & & & & & & & 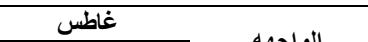 \\
\hline \multirow{3}{*}{$\sqrt{ }$} & & $\sqrt{ }$ & $\sqrt{ }$ & & & $\sqrt{ }$ & & & & & & الخاروفة \\
\hline & & & & & & & & & & & & مستوي \\
\hline & 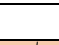 & $\sqrt{ }$ & $\sqrt{ }$ & & 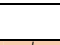 & $\sqrt{ }$ & & & & & & 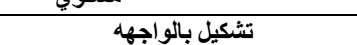 \\
\hline \multirow[t]{2}{*}{$\sqrt{ }$} & $\sqrt{ }$ & $\sqrt{ }$ & $\sqrt{ }$ & $\sqrt{ }$ & $\sqrt{ }$ & $\sqrt{ }$ & & & & & & زخارف وتثظطيات داخلية \\
\hline & & & $\sqrt{ }$ & $\sqrt{ }$ & $\sqrt{ }$ & & & $\sqrt{ }$ & $\sqrt{ }$ & J & $\sqrt{ }$ & \multirow{2}{*}{ عدد الأدوار } \\
\hline \multirow[t]{2}{*}{$\sqrt{ }$} & $\sqrt{ }$ & $\sqrt{ }$ & & & & $\sqrt{ }$ & & & & & & \\
\hline & & $\sqrt{ }$ & & & & & $\sqrt{ }$ & $\sqrt{ }$ & $\sqrt{ }$ & - & $\sqrt{ }$ & 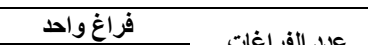 \\
\hline \multirow[t]{4}{*}{$\sqrt{ }$} & $\sqrt{ }$ & $\sqrt{ }$ & $\sqrt{ }$ & $\sqrt{ }$ & $\sqrt{ }$ & $\sqrt{ }$ & & & & $\sqrt{ }$ & & ع عدد العراعت \\
\hline & $\sqrt{ }$ & & $\sqrt{ }$ & & & $\sqrt{ }$ & $\sqrt{ }$ & $\sqrt{ }$ & $\sqrt{ }$ & $\sqrt{ }$ & $\sqrt{ }$ & مرتفعة (r> م م) \\
\hline & & $\sqrt{ }$ & & $\sqrt{ }$ & $\sqrt{ }$ & & & & & & & منذفضة (r) \\
\hline & $\sqrt{ }$ & & $\sqrt{ }$ & $\sqrt{ }$ & & $\sqrt{ }$ & $\sqrt{ }$ & $\sqrt{ }$ & $\sqrt{ }$ & $\sqrt{ }$ & $\sqrt{ }$ & \multirow{2}{*}{ نوع الصخور } \\
\hline \multirow[t]{2}{*}{ V } & & $\sqrt{ }$ & & & $\sqrt{ }$ & & & & & & & \\
\hline & & & & & & & & & & & & متحولة \\
\hline$\sqrt{ }$ & $\sqrt{ }$ & $\sqrt{ }$ & $\sqrt{ }$ & $\sqrt{ }$ & $\sqrt{ }$ & & & & & 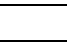 & & التدعيم الإنشائي \\
\hline & & & & & & & & & & & & الإضافي للبناء \\
\hline$\sqrt{ }$ & $\sqrt{ }$ & $\sqrt{ }$ & $\sqrt{ }$ & $\sqrt{ }$ & $\sqrt{ }$ & $\sqrt{ }$ & $\sqrt{ }$ & $\sqrt{ }$ & $\sqrt{ }$ & $\checkmark$ & $\sqrt{ }$ & المواد الإنشائية \\
\hline & & & & & & $\sqrt{ }$ & & & & & & للأسقة " \\
\hline$\sqrt{ }$ & $\sqrt{ }$ & $\sqrt{ }$ & $\sqrt{ }$ & $\sqrt{ }$ & $\sqrt{ }$ & $\sqrt{ }$ & $\sqrt{ }$ & $\sqrt{ }$ & $\sqrt{ }$ & v & $\sqrt{ }$ & المواد الإشثانية \\
\hline & & & & & & $\sqrt{ }$ & & & & & & للعوانط" \\
\hline$\sqrt{ }$ & $\sqrt{ }$ & $\sqrt{ }$ & $\sqrt{ }$ & $\sqrt{ }$ & $\sqrt{ }$ & $\sqrt{ }$ & $\sqrt{ }$ & $\sqrt{ }$ & $\sqrt{ }$ & $\sqrt{ }$ & $\sqrt{ }$ & المواد الإنشانية \\
\hline & & & & & & $\sqrt{ }$ & & & & & & للارضيات \\
\hline & $\sqrt{ }$ & $\sqrt{ }$ & $\sqrt{ }$ & $\sqrt{ }$ & & $\sqrt{ }$ & & & $\sqrt{ }$ & $\sqrt{ }$ & $\sqrt{ }$ & السفح \\
\hline & & $\sqrt{ }$ & & $\sqrt{ }$ & & & $\sqrt{ }$ & $\sqrt{ }$ & & & & موقع البناء \\
\hline$\sqrt{ }$ & & & & $\sqrt{ }$ & $\sqrt{ }$ & & & & & & & القمة \\
\hline$\sqrt{ }$ & & & & & $\sqrt{ }$ & & & & & & & مستوي مي مستو \\
\hline & & & & & & & & & & & & مائل (متوسط \\
\hline & $\sqrt{ }$ & & & & & & & $\sqrt{ }$ & & & & تلي (منددر) \\
\hline & & $\sqrt{ }$ & $\sqrt{ }$ & $\sqrt{ }$ & & $\sqrt{ }$ & $\sqrt{ }$ & & $\sqrt{ }$ & $\sqrt{ }$ & $\sqrt{ }$ & 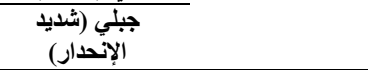 \\
\hline$\sqrt{ }$ & $\sqrt{ }$ & $\sqrt{ }$ & $\sqrt{ }$ & $\sqrt{ }$ & $\sqrt{ }$ & $\sqrt{ }$ & $\sqrt{ }$ & $\sqrt{ }$ & $\sqrt{ }$ & J & $\sqrt{ }$ & قطع (ق) \\
\hline & & & & & & & & & & & & 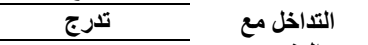 \\
\hline & & & & & & & & & & & & 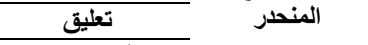 \\
\hline & & & & & & & & & & & & غير متلاخل \\
\hline & $\sqrt{ }$ & & & $\sqrt{ }$ & & & $\sqrt{ }$ & $\sqrt{ }$ & & & & المطل و التتو اصل البصري \\
\hline$\sqrt{ }$ & $\sqrt{ }$ & $\sqrt{ }$ & & & $\sqrt{ }$ & & & $\sqrt{ }$ & & & & لـلأعلي \\
\hline & & & & & & $\sqrt{ }$ & & & & $\sqrt{ }$ & & منسوب المدخل \\
\hline & & $\sqrt{ }$ & $\sqrt{ }$ & $\sqrt{ }$ & & & $\sqrt{ }$ & & $\sqrt{ }$ & & $\sqrt{ }$ & مستوي \\
\hline$\sqrt{ }$ & $\sqrt{ }$ & $\sqrt{ }$ & $\sqrt{ }$ & $\sqrt{ }$ & & $\sqrt{ }$ & $\sqrt{ }$ & $\sqrt{ }$ & $\sqrt{ }$ & J & $\sqrt{ }$ & أفقية \\
\hline & & & & & $\sqrt{ }$ & & & & & & & رأسية \\
\hline
\end{tabular}


جدول ؛. الجوانب التحليلية للنماذج المعمارية المختلفة (ץ) ـ المصدر: الباحث

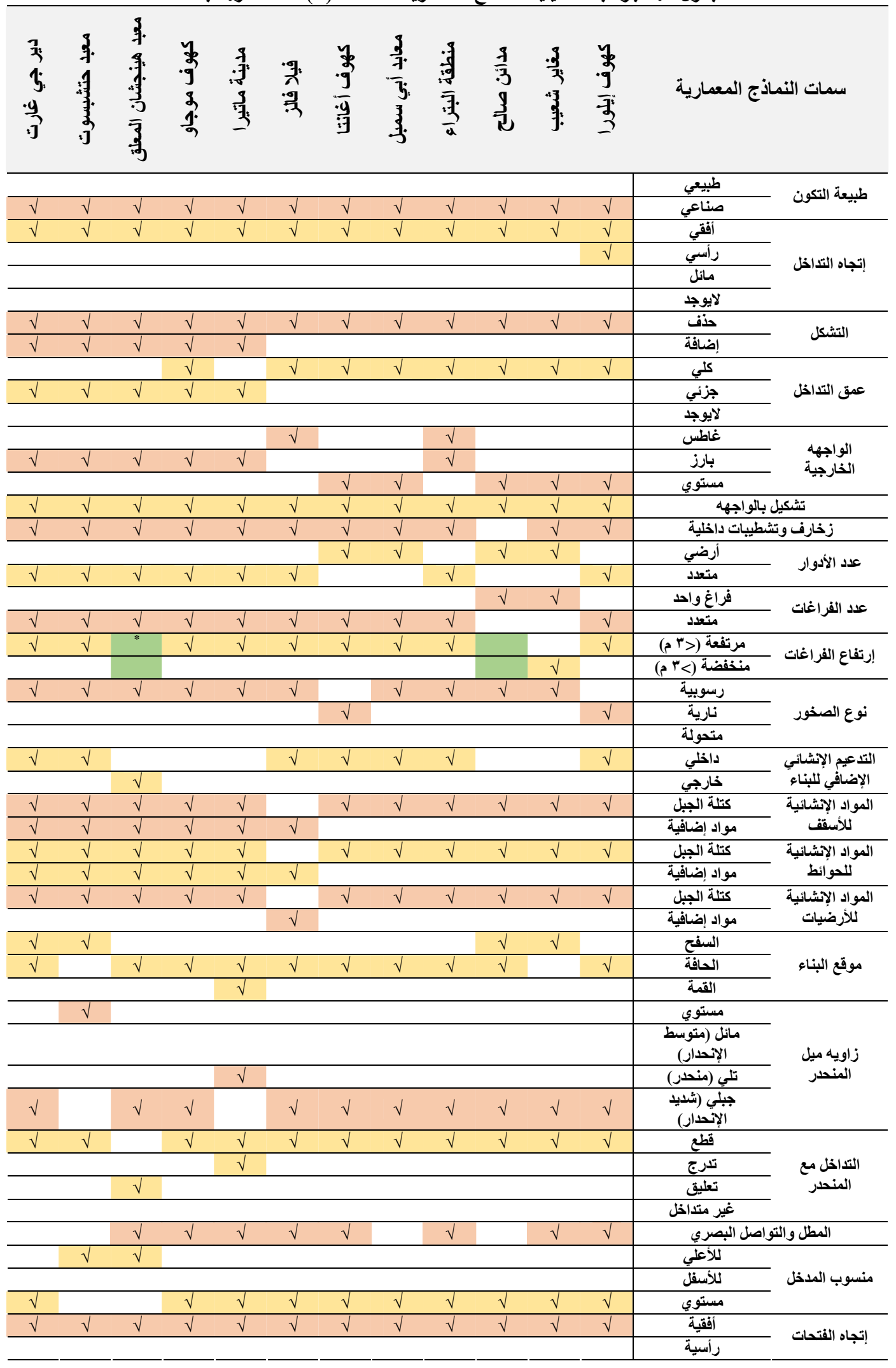


جدول ه. الجوانب التحليلية للنماذج المعمارية المختلفة (ب) ـ المصدر: الباحث

\begin{tabular}{|c|c|c|c|c|c|c|c|c|c|c|c|c|}
\hline 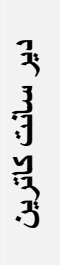 & 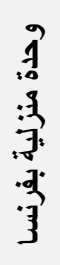 & 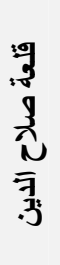 & 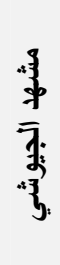 & $\begin{array}{l}\text { 慗 } \\
\text { 等 }\end{array}$ & $\frac{\frac{2}{3}}{\bar{\lambda}}$ & $\begin{array}{l}3 \\
3 \\
\text { 年: } \\
3 \\
3 \\
3 \\
3 \\
3\end{array}$ & $\begin{array}{l}\frac{1}{3} \\
\overline{7} \\
\frac{1}{3}\end{array}$ & $\begin{array}{l}\frac{9}{3} \\
\overline{7} \\
\frac{7}{9}\end{array}$ & 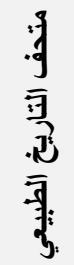 & $\begin{array}{l}3 \\
9 \\
\frac{7}{9} \\
\frac{7}{20}\end{array}$ & 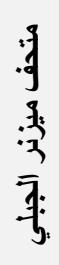 & سمات النماذج المعمارية \\
\hline & & & & & & & & & & & & طبيعي \\
\hline \multirow[t]{3}{*}{$\sqrt{ }$} & $\sqrt{ }$ & $\sqrt{ }$ & $\sqrt{ }$ & $\sqrt{ }$ & $\sqrt{ }$ & $\sqrt{ }$ & $\sqrt{ }$ & $\sqrt{ }$ & $\sqrt{ }$ & $\sqrt{ }$ & $\sqrt{ }$ & صناعي \\
\hline & $\sqrt{ }$ & & & & $\sqrt{ }$ & $\sqrt{ }$ & $\sqrt{ }$ & & $\sqrt{ }$ & $\sqrt{ }$ & $\sqrt{ }$ & أفقي \\
\hline & & & & & $\sqrt{ }$ & $\sqrt{ }$ & & & & & & إتجاه التداخل \\
\hline \multirow[t]{2}{*}{$\sqrt{ }$} & & $\sqrt{ }$ & $\sqrt{ }$ & $\sqrt{ }$ & & & & $\sqrt{ }$ & & & & لايوجد \\
\hline & & & & & & $\sqrt{ }$ & $\sqrt{ }$ & & $\sqrt{ }$ & $\sqrt{ }$ & $\sqrt{ }$ & حذف \\
\hline \multirow[t]{3}{*}{$\sqrt{ }$} & $\sqrt{ }$ & $\sqrt{ }$ & $\sqrt{ }$ & $\sqrt{ }$ & $\sqrt{ }$ & $\sqrt{ }$ & $\sqrt{ }$ & $\sqrt{ }$ & $\sqrt{ }$ & $\sqrt{ }$ & $\sqrt{ }$ & إضافة \\
\hline & & & & & & & & & & & & كلي \\
\hline & & & & $\sqrt{ }$ & $\sqrt{ }$ & $\sqrt{ }$ & $\sqrt{ }$ & & $\sqrt{ }$ & $\sqrt{ }$ & $\sqrt{ }$ & عمق التلاخل \\
\hline \multirow[t]{2}{*}{$\sqrt{ }$} & $\sqrt{ }$ & $\sqrt{ }$ & $\sqrt{ }$ & & & & & $\sqrt{ }$ & & & & لايوجذ ل اليا \\
\hline & & & & & & & & & & $\sqrt{ }$ & & غاطس - | غاطس \\
\hline \multirow[t]{2}{*}{$\sqrt{ }$} & $\sqrt{ }$ & $\sqrt{ }$ & $\sqrt{ }$ & $\sqrt{ }$ & $\sqrt{ }$ & $\sqrt{ }$ & $\sqrt{ }$ & $\sqrt{ }$ & $\sqrt{ }$ & $\sqrt{ }$ & $\sqrt{ }$ & الواجهاه الخارجية \\
\hline & & & & & & & & & & & & مستوي \\
\hline$\sqrt{ }$ & $\sqrt{ }$ & $\sqrt{ }$ & $\sqrt{ }$ & $\sqrt{ }$ & $\sqrt{ }$ & $\sqrt{ }$ & $\sqrt{ }$ & $\sqrt{ }$ & $\sqrt{ }$ & $\sqrt{ }$ & $\sqrt{ }$ & تثكيل بالواجهه \\
\hline \multirow[t]{2}{*}{$\sqrt{ }$} & $\sqrt{ }$ & $\sqrt{ }$ & $\sqrt{ }$ & $\sqrt{ }$ & $\sqrt{ }$ & $\sqrt{ }$ & $\sqrt{ }$ & $\sqrt{ }$ & $\sqrt{ }$ & $\sqrt{ }$ & $\sqrt{ }$ & زخارف وتثطيبات داخلية \\
\hline & $\sqrt{ }$ & $\sqrt{ }$ & $\sqrt{ }$ & $\sqrt{ }$ & & & $\sqrt{ }$ & & & $\sqrt{ }$ & & 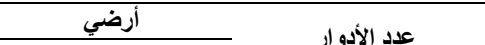 \\
\hline \multirow[t]{2}{*}{$\sqrt{ }$} & & & & & $\sqrt{ }$ & $\sqrt{ }$ & & $\sqrt{ }$ & $\sqrt{ }$ & & $\sqrt{ }$ & متعدد \\
\hline & & & & & & & & & & & & فراغ واحل \\
\hline \multirow[t]{4}{*}{$\sqrt{ }$} & $\sqrt{ }$ & $\sqrt{ }$ & $\sqrt{ }$ & $\sqrt{ }$ & $\sqrt{ }$ & $\sqrt{ }$ & $\sqrt{ }$ & $\sqrt{ }$ & $\sqrt{ }$ & $\sqrt{ }$ & $\sqrt{ }$ & متعلد \\
\hline & & & & & & & & & $\sqrt{ }$ & & $\sqrt{ }$ & مرتفعة (ب> م) مر \\
\hline & & & & & & & & $\sqrt{ }$ & & $\sqrt{ }$ & & منفضضة (>> م) \\
\hline & & $\sqrt{ }$ & $\sqrt{ }$ & $\sqrt{ }$ & $\sqrt{ }$ & 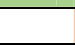 & $\sqrt{ }$ & $\sqrt{ }$ & & & $\sqrt{ }$ & رسوبية \\
\hline$\sqrt{ }$ & $\sqrt{ }$ & & & & & $\sqrt{ }$ & & & $\sqrt{ }$ & $\sqrt{ }$ & & نوع الصخور \\
\hline$\sqrt{ }$ & & & & & & & & & & & & 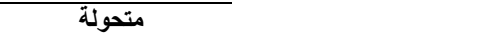 \\
\hline \multirow[t]{3}{*}{$\sqrt{1}$} & & $\sqrt{ }$ & $\sqrt{ }$ & $\sqrt{ }$ & $\sqrt{ }$ & $\sqrt{ }$ & $\sqrt{ }$ & $\sqrt{ }$ & $\sqrt{ }$ & & $\sqrt{ }$ & التدعيم الإنشائي الإضافي \\
\hline & & & & $\sqrt{ }$ & & & & $\sqrt{ }$ & & & & خارجي \\
\hline & & & & & & & $\sqrt{ }$ & & & $\sqrt{ }$ & & كتلة الجبل \\
\hline \multirow[t]{2}{*}{$\sqrt{ }$} & $\sqrt{ }$ & $\sqrt{ }$ & $\sqrt{ }$ & $\sqrt{ }$ & $\sqrt{ }$ & $\sqrt{ }$ & $\sqrt{ }$ & $\sqrt{ }$ & $\sqrt{ }$ & & $\sqrt{ }$ & مو اد إضافية \\
\hline & & & & & & & $\sqrt{ }$ & & & $\sqrt{ }$ & & كتلة الجبل \\
\hline$\sqrt{ }$ & $\sqrt{ }$ & $\sqrt{ }$ & $\sqrt{ }$ & $\sqrt{ }$ & $\sqrt{ }$ & $\sqrt{ }$ & $\sqrt{ }$ & $\sqrt{ }$ & $\sqrt{ }$ & $\sqrt{ }$ & $\sqrt{ }$ & 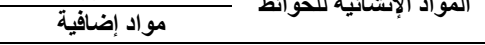 \\
\hline \multirow[t]{4}{*}{$\sqrt{ }$} & $\sqrt{ }$ & & & & $\sqrt{ }$ & & $\sqrt{ }$ & & & $\sqrt{ }$ & & المواد الإنشائية \\
\hline & & $\sqrt{ }$ & $\sqrt{ }$ & $\sqrt{ }$ & $\sqrt{ }$ & $\sqrt{ }$ & & $\sqrt{ }$ & $\sqrt{ }$ & & $\sqrt{ }$ & مو اد إضافية \\
\hline & & & & & & & & & $\sqrt{ }$ & $\sqrt{ }$ & & السفح السف \\
\hline & & & & & & & $\sqrt{ }$ & $\sqrt{ }$ & & & & موقع البناء \\
\hline$\sqrt{ }$ & $\sqrt{ }$ & $\sqrt{ }$ & $\sqrt{ }$ & $\sqrt{ }$ & $\sqrt{ }$ & $\sqrt{ }$ & & & & & $\sqrt{ }$ & القمة القمة \\
\hline \multirow[t]{7}{*}{$\sqrt{ }$} & $\sqrt{ }$ & $\sqrt{ }$ & $\sqrt{ }$ & & $\sqrt{ }$ & & & & & & $\sqrt{ }$ & مستوي \\
\hline & & & & & & & & & & & & مائل (متوسط الإنحدار) \\
\hline & & & & & & & & & & & & تلي (منحلر) \\
\hline & & & & $\sqrt{ }$ & & $\sqrt{ }$ & $\sqrt{ }$ & $\sqrt{ }$ & $\sqrt{ }$ & $\sqrt{ }$ & & جبلي (شديد الإنحار) \\
\hline & & & & & $\sqrt{ }$ & $\sqrt{ }$ & $\sqrt{ }$ & & & $\sqrt{ }$ & & قطع \\
\hline & $\sqrt{ }$ & & & & $\sqrt{ }$ & $\sqrt{ }$ & $\sqrt{ }$ & & $\sqrt{ }$ & & $\sqrt{ }$ & التذاخل مع المنحدر \\
\hline & & & & & & & & $\sqrt{ }$ & & & & إس \\
\hline \multirow[t]{4}{*}{$\sqrt{ }$} & & $\sqrt{ }$ & $\sqrt{ }$ & $\sqrt{ }$ & & & & & & & & غير متلاخل \\
\hline & $\sqrt{ }$ & $\sqrt{ }$ & $\sqrt{ }$ & $\sqrt{ }$ & $\sqrt{ }$ & $\sqrt{ }$ & $\sqrt{ }$ & $\sqrt{ }$ & $\sqrt{ }$ & & $\sqrt{ }$ & المطل والتو اصل البصري \\
\hline & & & & & $\sqrt{ }$ & $\sqrt{ }$ & & & & $\sqrt{ }$ & & 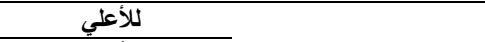 \\
\hline & & & & & & & & & & & & منسوب المدلل \\
\hline$\sqrt{ }$ & $\sqrt{ }$ & $\sqrt{ }$ & $\sqrt{ }$ & $\sqrt{ }$ & & $T_{T}$ & $\sqrt{ }$ & $\sqrt{ }$ & $\sqrt{ }$ & & $\sqrt{ }$ & مستوي \\
\hline \multirow[t]{2}{*}{$\sqrt{ }$} & $\sqrt{ }$ & $\sqrt{ }$ & $\sqrt{ }$ & $\sqrt{ }$ & $\sqrt{ }$ & $\sqrt{ }$ & $\sqrt{ }$ & $\sqrt{ }$ & $\sqrt{ }$ & $\sqrt{ }$ & $\sqrt{ }$ & إتجاه الفتحات \\
\hline & & & & $\sqrt{ }$ & & & & & $\sqrt{ }$ & & & إجباه إعضا \\
\hline
\end{tabular}

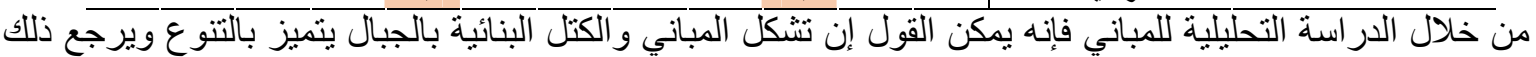

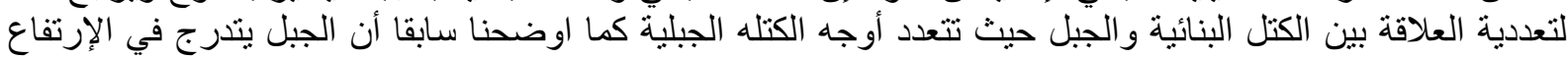


لأعلي ولذلك فإن كل جزء منه ووفقا لتضاريسه وميوله يسمح بإمكانية البناء لأنو اع محددة من المباني وقد يكون بعضها الإنها

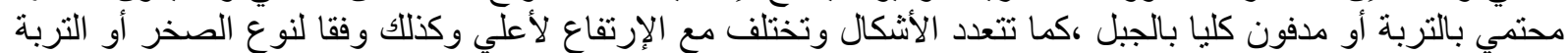

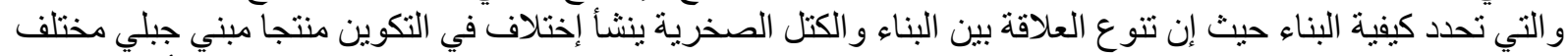

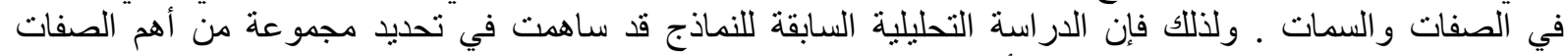

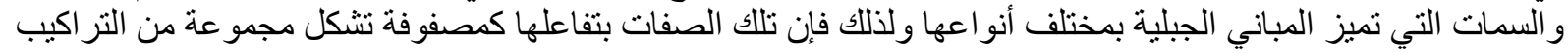

جدول "7. اهم الصفات التي تساهم في تكون البناء الجبلي ـ المصدر: الباحث

المعمارية ،وتلاك النقاط موضحة فيز في جدول 7 . إتجاه التداخل بالصخور الباحر

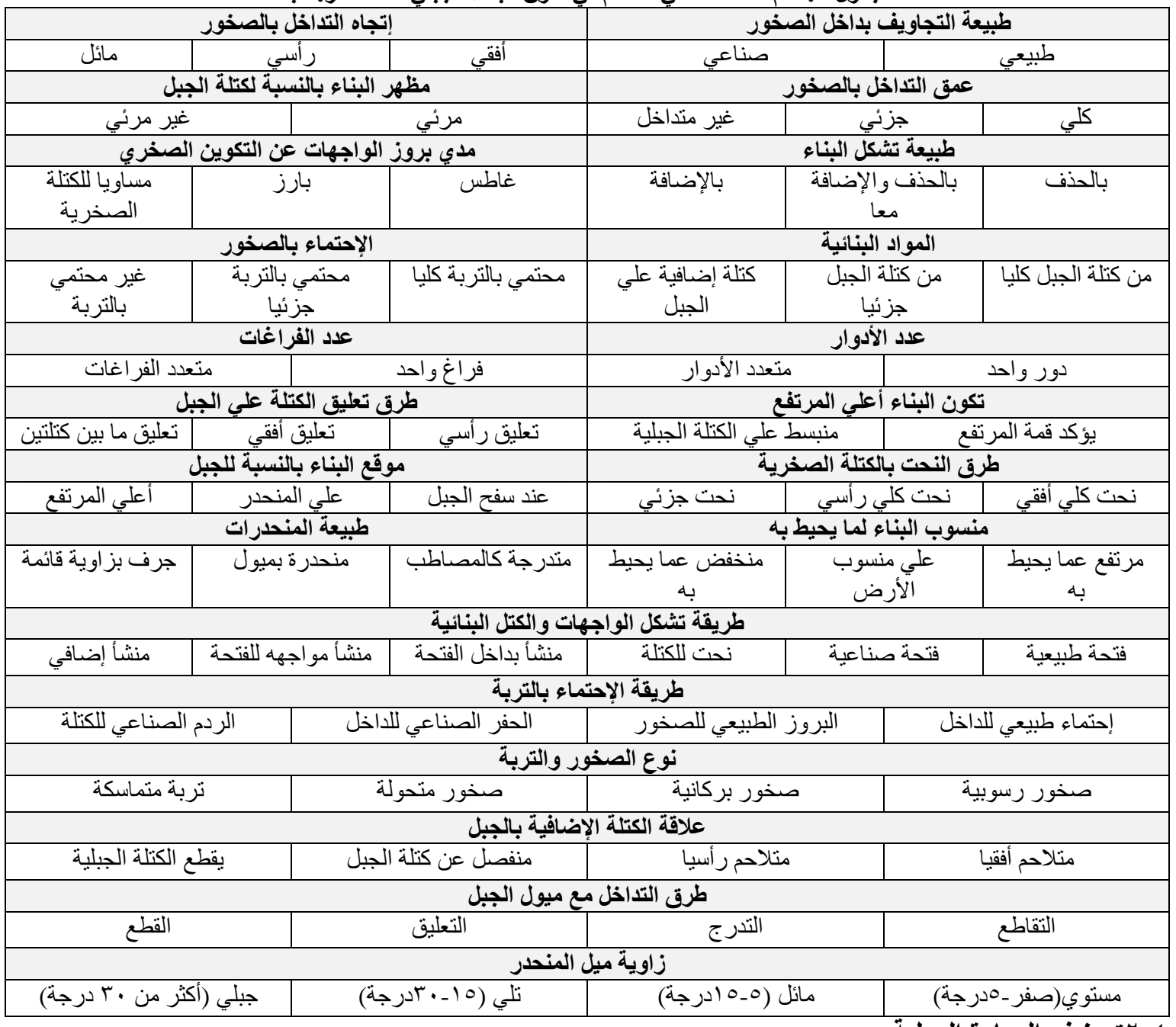

ـ ـ ب اتصنيف العمارة الجبلية

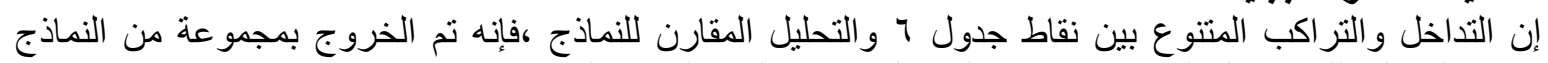

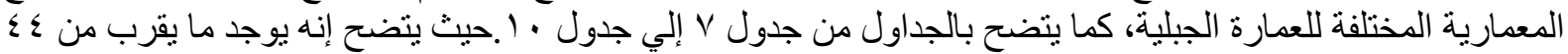
نوع مختلف من المباني الجبلية والتي بواسطتها يمكن اطلاق ما يسمي بالعمارة الجبلية والبناء الجبلي كمعمار مستقل ومنفصل عن باقي التصنيفات المعمارية العالمية. 


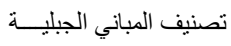

جدول V. تصنيفات المباني الجبلية وفقا للاراسة التحليلية ( 1) ـ المصدر: الباحث

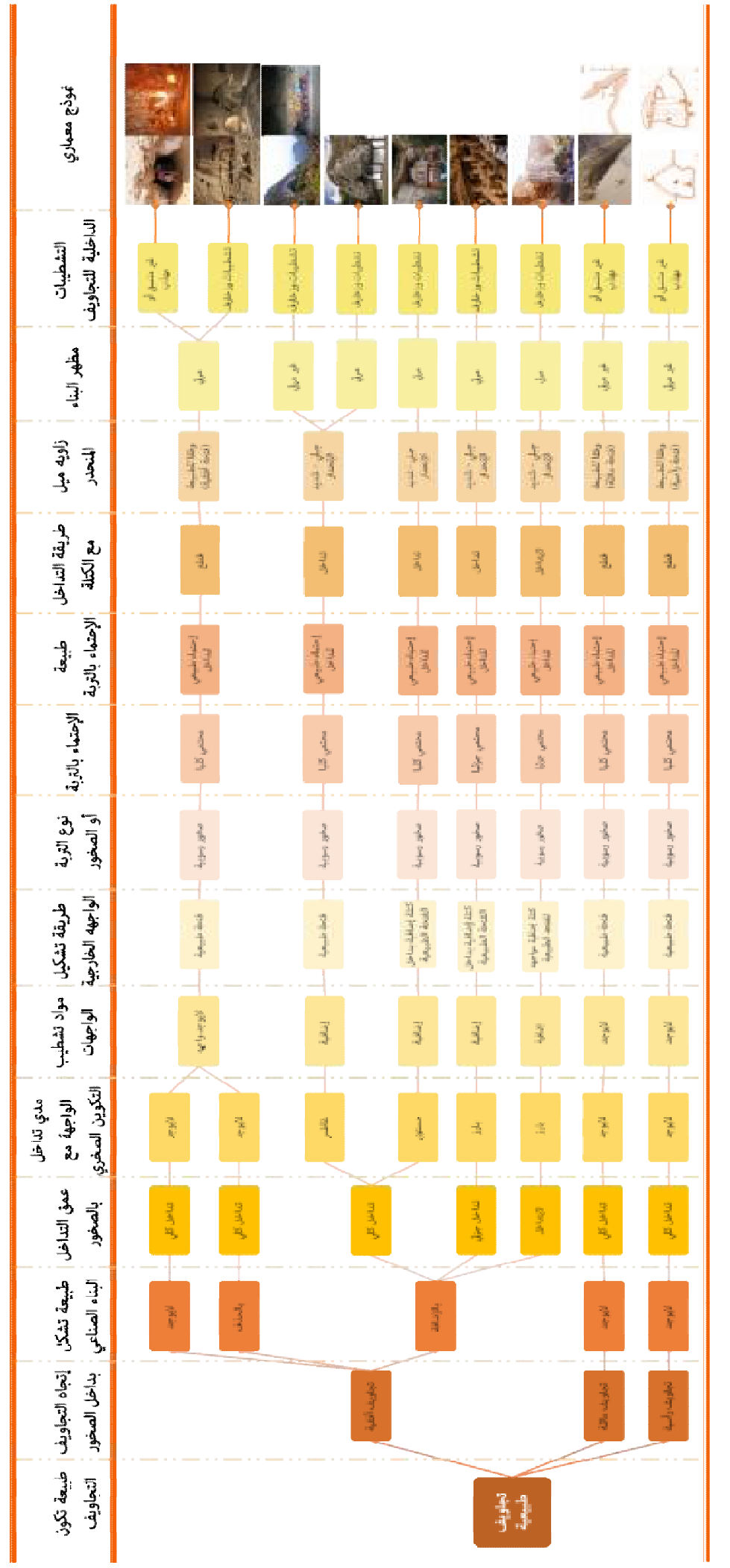




$$
\text { تصنيف المباني الجبليــة }
$$

جدول ^. تصنيفات المباني الجبلية وفقا للاراسة التحليلية (ץ) ـ المصدر: الباحث

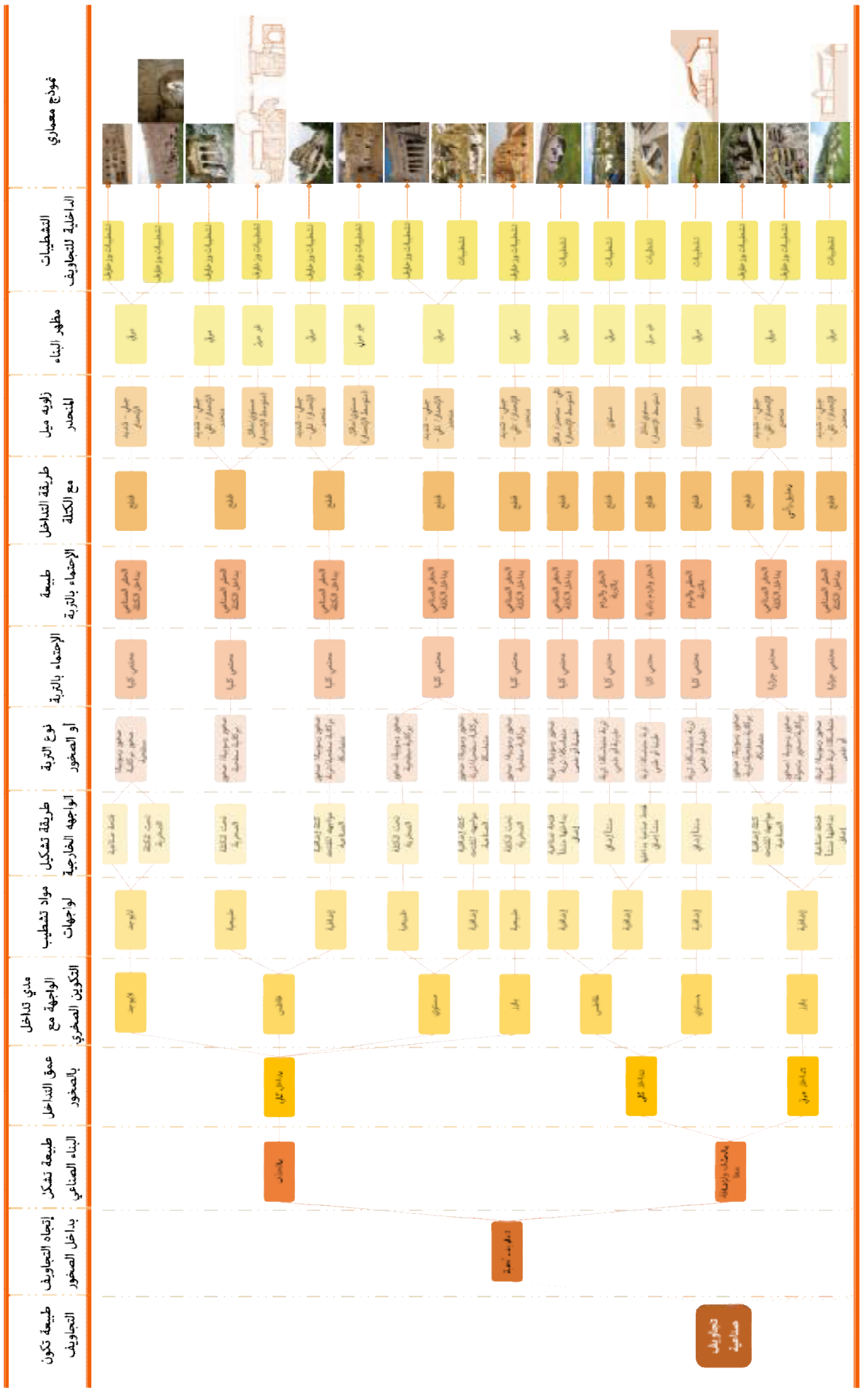




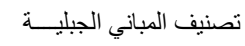

جدول 9.

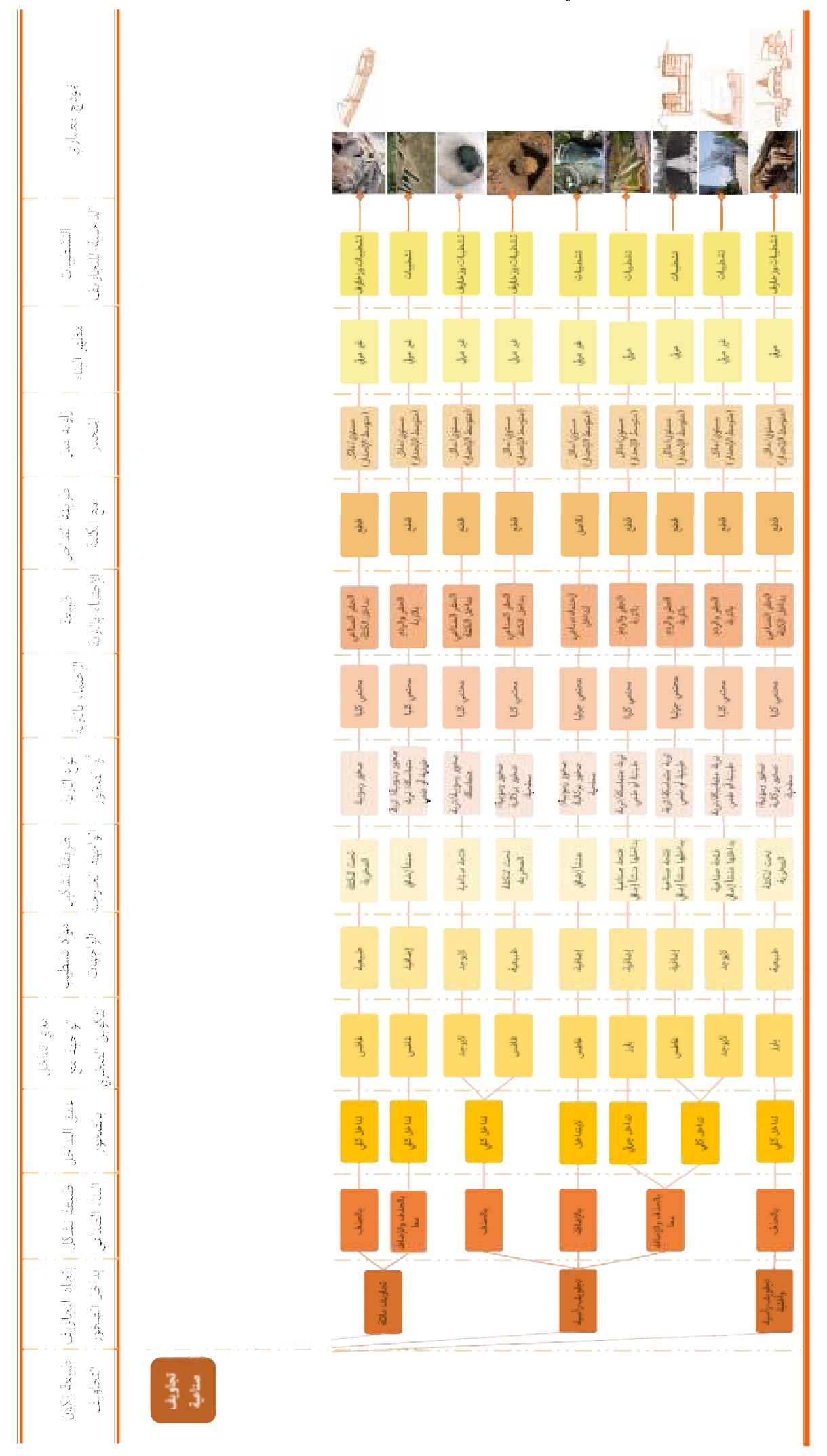




$$
\text { تصنيف المباني الجبليـة }
$$

جدول · 1. تصنيفات المباني الجبلية وفقا للاراسة التحليلية (؛) ـ المصدر: الباحث

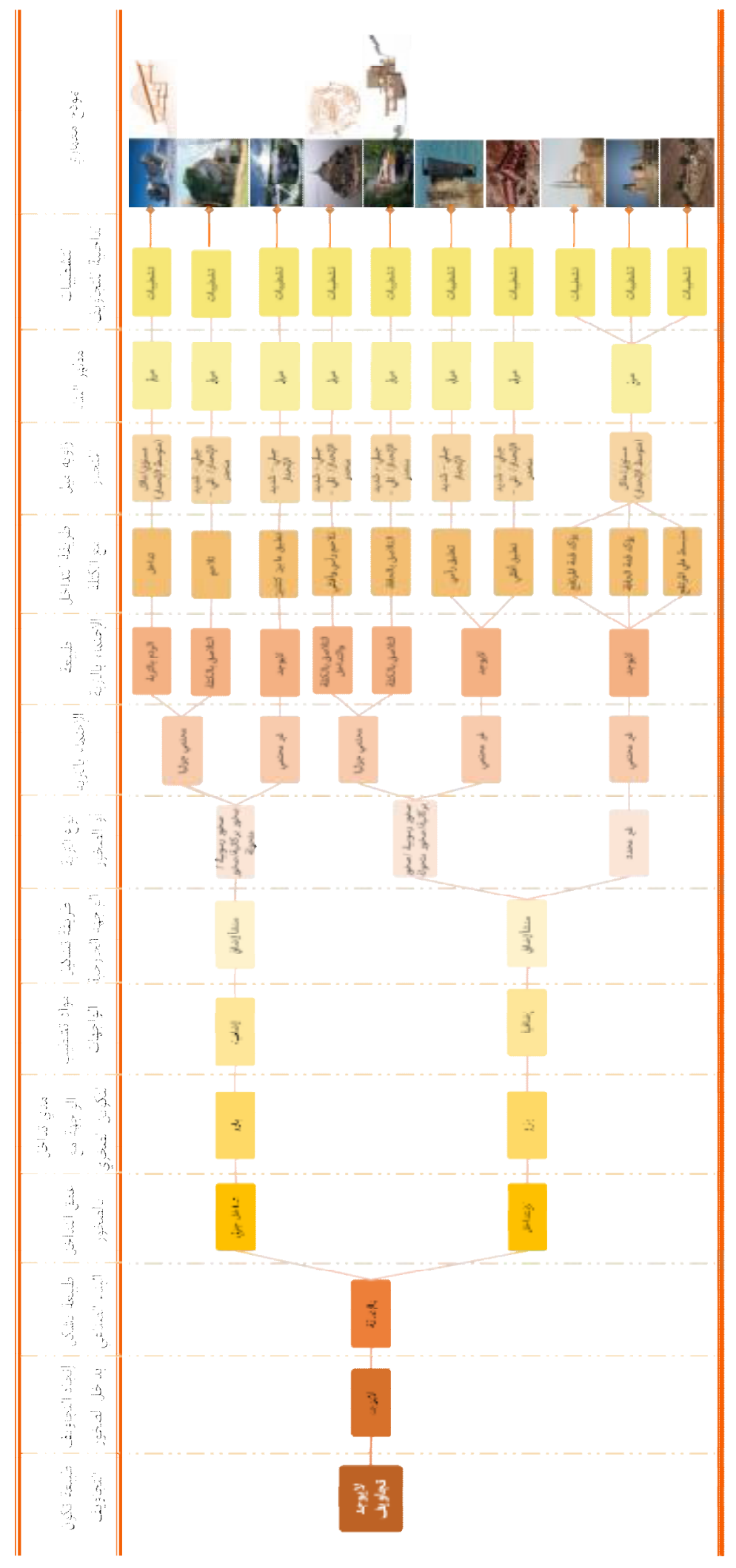


إن عمارة الجبال هي نوع مختلف من المعمار حيث التتوع في طرق البناء المعماري وذلك نظر الغني الغني المناطق الجبلية

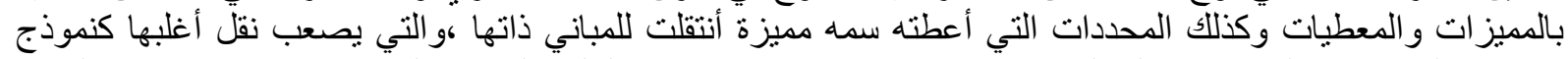

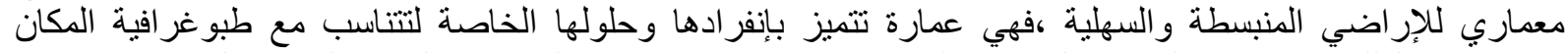

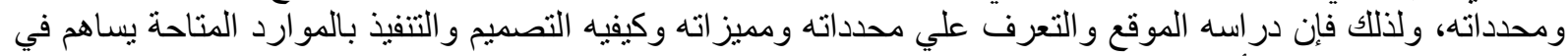

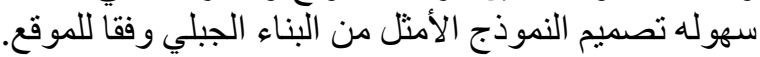

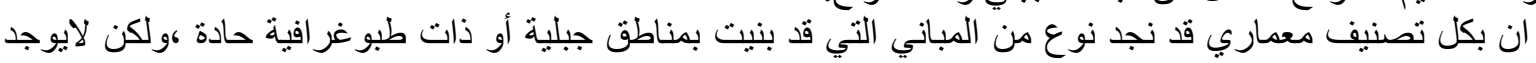

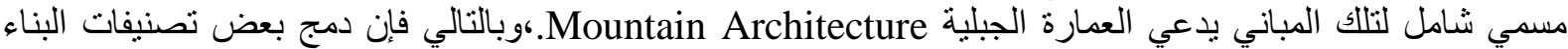

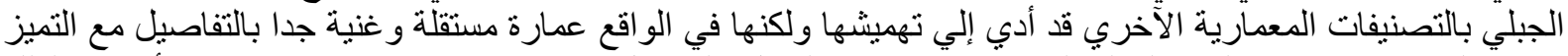

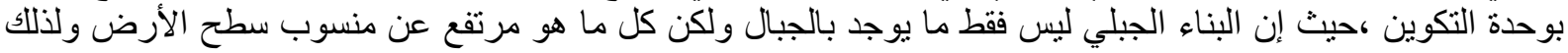

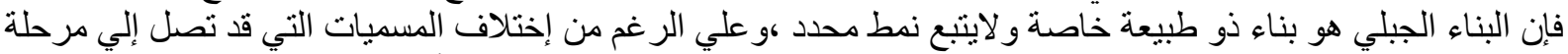

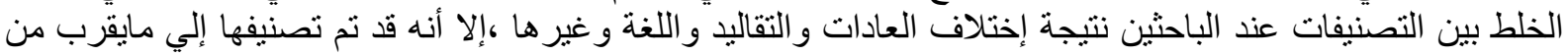

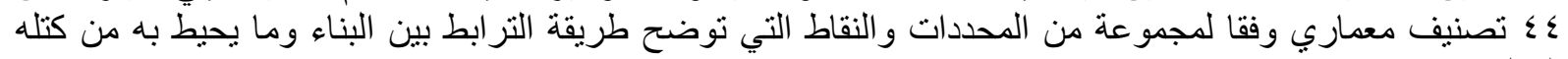

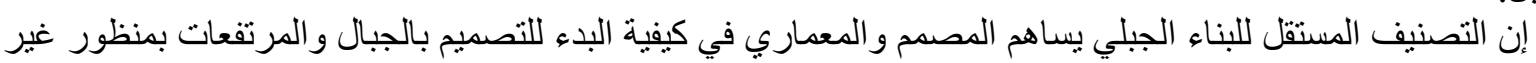

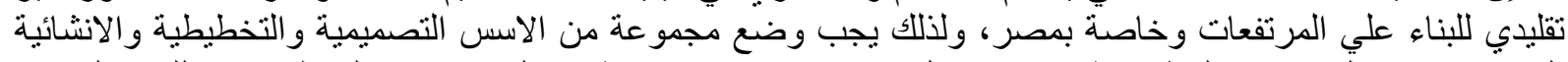

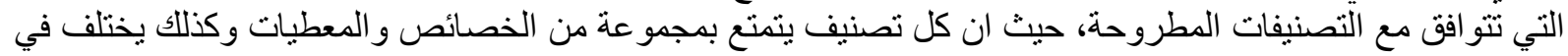
طريقة التنفيذ والمو اد المطلوبه للإنشاء.

[1] Klodt G. Earth sheltered housing. Reston,Virginia: Reston publishing company,A

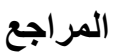
Prentice-Hall company; 1985.

[2] Crescenzi C, Caprara R, editors. Common Identity - New Perspective THE RUPESTRIAN SETTLEMENTS IN THE CIRCUM-MEDITERRANEAN AREA. Firenze: Università degli studi di Firenze; 2012.

[3] Correia, M., Dipasquale, L., \& Mecca S. Heritage for tomorrow. 2010.

[4] Roy R. the Complete Book of Underground Houses-How To Build a Low-Cost Home. New York: Sterling Publication Co., INC.; 1994.

[5] Noble AG. Traditional Buildings: A Global Survey of Structural Forms and Cultural Functions. London: I.B. Tauris; 2007.

[6] Thefreedictionary. Troglodyte n.d. http://www.thefreedictionary.com/troglodyte (accessed October 24, 2017).

[7] Golany GS. Chinese Earth-Sheltered Dwellings: Indigenous Lessons for Modern Urban Design. United States of America: University of Hawaii Press; 1992.

[8] Wines J. Green Architecture. Koln, Germany.: Taschen GmbH; 2008.

[9] Thefreedictionary. Excavate n.d. https://www.thefreedictionary.com/excavated (accessed October 24, 2017).

[10] Thefreedictionary. subterranean n.d. http://www.thefreedictionary.com/subterranean (accessed October 24, 2017).

[11] Yourdictionary. rupestrian n.d. http://www.yourdictionary.com/rupestrian (accessed October 24, 2017).

فجال خ. "العمارة و البيئة في المناطق الصحر اوية الحارة. القاهرة: دار النصر للطباعة الإسلامية؛ ب . . r.

[13] Culver D, Papon T. The biology of caves and other subterranean habitats. New York: Oxford University Press; 2010.

[14] Pastoors A, Weniger GC. Cave Art in Context: Methods for the Analysis of the Spatial Organization of Cave Sites. J Archaeol Res 2011;19:377-400. doi:10.1007/s10814011-9050-5.

[15] Aydogan M. Caves of Turkey. Nat Herit from East to West Case Stud from 6 EU Ctries 2010:287-300. doi:10.1007/978-3-642-01577-9.

[16] Fletcher B. A History of Architecture. Twentieth. Daryaganj, New Delhi: CBS 
Publishers \& Distributors Pvt. Ltd; 1996.

[17] Merriam-webster. Grotto n.d.

[18] Thefreedictionary. Hypogeal n.d. https://www.thefreedictionary.com/hypogeal (accessed October 24, 2017).

[19] Sterling R. Earth sheltered Residential Design Manual. United States of America: Underground space center, university of Minnesota, Van Nostrand Reinhold company; 1982.

[20] Terman M. EARTH SHELTERED HOUSING: Principles in Practice. New York: VAN NOSTRAND REINHOLD COMPANY; 1985. doi:10.1007/978-1-4684-6644-7.

[21] Sterling R, Carmody J, Elinicky G. Earth sheltered community Design:EnergyEfficient Residential Development. USA: Underground Space center, University of Minnesota,Van Nostrand Reinhold company Ink; 1979.

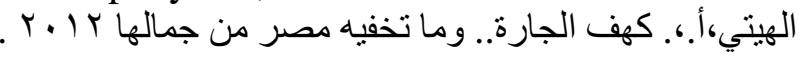

https://news.travelerpedia.net/destinations/ (accessed May 6, 2014).

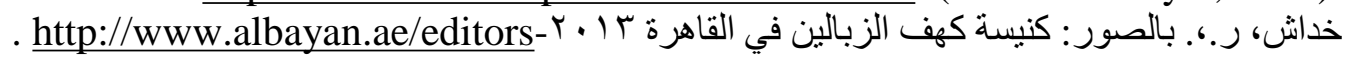
choice/varity/2013-09-12-1.1958350 (accessed September 12, 2014).

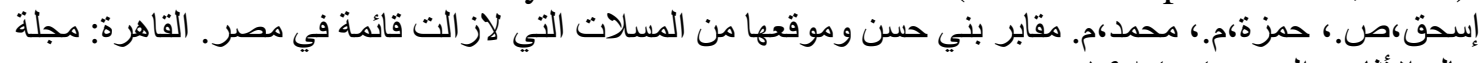

[25] UNESCO World Heritage List. Ellora Caves n.d. http://whc.unesco.org/en/list/243 (accessed February 17, 2014).

[26] Raezer D, Raezer J. The Caves of India: Ajanta, Ellora and Elephanta. New York, NY: Approach Guides; 2015.

[27] Villavals. The design of Villa Vals n.d. http://www.villavals.ch/design.php (accessed February 17, 2014).

[28] atlasobscura. Hanging Temple of Hengshan - A 5th-century temple improbably built into the side of a cliff n.d. http://www.atlasobscura.com/places/hanging-templehengshan (accessed February 17, 2014).

نايل،م.، عبدالقادر،م. تاريخ فن العمارة ـالجزء الأول. القاهرة: وزارة المعارف العمومية، المطبعة الأميرية

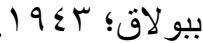

[30] Zimmer L. Modscape's Cliff House Hangs Perilously Over a Cliff's Edge in Australia 2014. http://inhabitat.com/modular-cliff-house-hangs-perilously-over-a-cliffs-edge-inaustralia (accessed July 9, 2014).

[31] Kitching C. Supertide of the century: Thousands of tourists descend on French city of Mont Saint-Michel to witness spectacular event sparked by the solar eclipse 2015.

[32] Marché L. Mont Saint-Michel 2008. http://www.ot-montsaintmichel.com/

FCKeditor/UserFiles/GB-2016.pdf. 
تصنيف المباني الجبليـــة 